\title{
Slab temperature evolution over the lifetime of a subduction zone
}

\author{
A. F. Holt ${ }^{1}$ and C. B. Condit ${ }^{2}$ \\ 1: Rosenstiel School of Marine and Atmospheric Sciences, University of Miami, Miami, FL. \\ 2: Department of Earth and Space Sciences, University of Washington, Seattle, WA.
}

Corresponding author: Adam F. Holt (aholt@miami.edu)

ORCIDs: 0000-0002-7259-0279 (Holt), 0000-0001-5024-9101 (Condit)

Twitter handles: @AdamFHolt @CailCon

Please cite the version published in Geochemistry, Geophysics, Geosystems:

Holt, A. F., and Condit, C. B., 2021. Slab temperature evolution over the lifetime of a subduction zone. Geochem., Geophys., Geosys., 22, e2020GC009476, https://doi.org/10.1029/2020GC009476 


\section{ABSTRACT}

1 The thermal evolution of subducting slabs controls a range of subduction processes, yet we lack

2 a robust understanding of how thermal structure develops over a subduction zone's lifetime. We

3 investigate the time-dependence of slab thermal structure using dynamically consistent, time

4 evolving models. Pressure-temperature $(P-T)$ conditions along the slab Moho and slab top

5 exhibit substantial variability throughout the various phases of subduction: initiation, free

6 sinking, mature subduction. This variability occurs in response to time-dependent subduction

7 properties (e.g., fast vs. slow convergence) and thermal structure inherited from previous phases

8 (e.g., due to upper plate aging). At a given depth, the slab cools rapidly during initiation, after

9 which slower cooling occurs. In the case of the Moho, additional cooling occurs during the free

10 sinking phase. We explore the implications of time-dependent thermal structure on exhumed

11 rocks and slab dehydration. Modeled slab top $P-T$ paths span much of the $P-T$ space associated

12 with exhumed rocks, suggesting a significant component of recorded variability may have

13 dynamic origins. Coupling our $P-T$ profiles with thermodynamic models of oceanic lithosphere,

14 we show that dehydrating ultramafic rocks at the slab Moho provide the bulk of hydrous fluid at

15 subarc depths during the earliest phases. Over subsequent phases, these rocks carry fluids into

16 the deeper mantle, and it is mafic crust along the slab top that releases water at subarc depths.

17 We conclude that varying subduction conditions, and non-steady-state thermal structure,

18 challenge the utility of kinematically-driven models with constant subduction parameters,

19 particularly for investigating thermal structure in the geological past. 


\section{INTRODUCTION}

20 The thermal structure of subduction zones enacts a first order control on a wide range of

21 subduction processes and properties, from the rheological strength of an individual plate

22 interface to material transport, chemical transformations, and global element cycling. This

23 thermal structure contributes to element cycling by affecting the locus and magnitude of

24 devolatilization, and the amount of volatiles that subduct past the arc and into the deeper mantle

25 (Hacker, 2008; Rüpke et al., 2004). Given the importance of these thermally controlled

26 processes, a longstanding goal of subduction research is a quantitative understanding of

27 subduction zone thermal structure.

While analytical and semi-analytical models established the first-order controls on subduction zone temperature fields (McKenzie, 1969; 1970) and subsequently refined thermal estimates (e.g., Molnar and England, 1990; 1995; Royden, 1993; Davies, 1999), the thermal structure of subduction zones is now most commonly investigated using numerical calculations of mantle wedge flow (e.g., Furukawa, 1993; van Keken et al., 2002; Currie et al., 2004). These models typically prescribe the kinematic behavior of the subducting plate and calculate the resulting thermal solution for the mantle wedge. Use of specific subduction parameters makes such models readily applicable to individual currently active subduction zones and so, when constrained using geophysical or petrological observables, they have led to important insights about Earth's down-going water flux (Syracuse et al., 2010; van Keken et al., 2011), drivers of arc magmatism (e.g., Grove et al., 2009; Perrin et al., 2018), and exhumation potential of subduction zone rocks (Gerya et al., 2002; van Keken et al., 2018). In most such models, steady or quasi-steady state thermal structure is computed by either neglecting the time-derivative in the energy equation or by holding subduction properties constant over tens of Myr. Alternatively, time dependence can be introduced by either varying imposed subduction properties like convergence rate (e.g., Peacock and Wang, 1999; Suenaga et al., 2019) or by examining the transient phase in models that impose constant properties yet retain time dependence in the energy equation (e.g., Hall, 2012). However, because these approaches all impose slab and plate properties, they are unable to investigate the time-dependence of subduction zone thermal structure (and associated non-steady state effects) within a framework that permits the slab, plates, and mantle wedge to co-evolve in a dynamically consistent manner.

Tectonic and plate kinematic observations demonstrate that the properties governing slab temperatures, such as slab dip, convergence rate, and upper plate structure, can vary over fewMyr timescales (e.g., Faccenna et al., 2001; Sdrolias and Müller et al., 2006; Iaffaldano, 2015). Such observations are supported by similarly fast subduction zone variation in dynamic subduction models (Clark et al., 2008; Cerpa et al., 2014), with models exhibiting distinct phases throughout the lifetime of a subduction zone that can last for several Myrs and are characterized 
by differing plate motions, trench motions, and/or slab dips (e.g., Funiciello et al., 2004; Garel et al., 2014; Holt et al., 2015). Given this inherent subduction zone time dependence, and the links between subduction properties and thermal structure, it is then unsurprising that strongly timedependent pressure-temperature $(P-T)$ conditions are recorded in the metamorphic rocks exhumed at a wide range of paleo subduction zones (e.g., Lázaro et al., 2009; Groppo et al., 2009; Krebs et al., 2011).

Motivated by this, we use time-dependent and self-consistently evolving numerical models to investigate the imprint that dynamic changes in subduction behavior have on slab Moho and slab top temperature. For convenience, we refer to our models as 'dynamic' and the more common mantle wedge models that prescribe slab and overriding plate properties as either 'kinematicdynamic' or 'kinematically-driven' models. That is, the latter set of models kinematically prescribe the slab and upper plate behavior but derive a dynamic solution for flow and thermal structure in the mantle wedge. We note that some thermal subduction models fall between these endmembers, e.g., models that include flow in the wedge that is driven by compositional density anomalies (e.g., Gerya et al., 2002; Gerya and Yuen, 2003) or prescribe plate velocities but solve for slab evolution and/or upper plate deformation (e.g., Eberle et al., 2002; Yamato et al., 2007; Arcay, 2012; 2017). However, only a limited set of studies have examined the detailed evolution of slab pressure-temperature $(P-T)$ conditions within models that do not impose any external forces or velocities on the flow (King and Ita, 1995; Kincaid and Sacks, 1997). While dynamic models are challenging to tailor to specific subduction zones, they allow us to develop intuition about time-dependent and non-steady-state thermal structure in a generalized sense. At the scale of an individual subduction zone, such an understanding is needed to move towards: i) accounting for thermal structure that has been inherited from previous phases in present day thermal structure estimates, ii) assessing how rapidly thermal structure varies, and iii) constraining how temperature-dependent observables may vary within the geological record.

Temporal changes in subduction zone thermal structure can be expected to manifest in a range of geological phenomena. After fingerprinting the various phases of subduction zone thermal structure, we also use our models to assess the relations of slab temperature variations on two phenomena: $P-T$ conditions recorded in exhumed rocks, and dehydration depths and magnitudes within the downgoing lithosphere. The exhumed rock record reflects subduction zone temperatures that are, in general, warmer than the equivalent temperatures in modeled subduction zones by $\geq 100^{\circ} \mathrm{C}$ (Guillot et al., 2009; Penniston-Dorland et al. 2015; Gerya et al., 2002; Syracuse et al., 2010). In addition to a potential contribution from additional heat sources, including shear heating which can increase slab top temperatures most substantially at depths undergoing frictional deformation $<\sim 50$ km (e.g., Peacock, 1992; Gao and Wang, 2014;

\section{Penniston-Dorland et al. 2015), preferential exhumation of subduction terranes during} particularly hot phases of subduction and/or at young subduction zones offer alternative explanations (e.g., Abers et al., 2017; van Keken et al., 2018). Our models enable us to develop a dynamically consistent basis for the various thermal phases that a subduction zone evolves 
through, from subduction initiation to mature subduction. We find that the resulting timedependence of crustal temperature is, in a single model subduction zone, significant enough to cover a significant proportion of the $P-T$ space recorded by exhumed rocks. That is, our modeled slab top paths overlay all of the $P-T$ space occupied by exhumed rocks aside from that represented by only the very warmest (i.e., metamorphic soles) and very highest pressure rocks.

For subduction zone models with a range of mechanical parameters (slab strength, crust viscosity and rheology, lower mantle viscosity), slab tops undergo rapid cooling during subduction initiation followed by cooling at a reduced rate during the latter phases. The slab Moho undergoes a similar thermal evolution but with the addition of a 5 to $10 \mathrm{Myr}$ long cooling transient that occurs as the slab sinks rapidly through the relatively weak upper mantle. When such $P$ - $T$ conditions are coupled with thermodynamic models of oceanic crust and mantle dehydration, they suggest strong temporal variability in the degree and location of oceanic lithosphere dehydration throughout the lifetime of a subduction zone. Fluid sources within the subarc mantle are likely from dehydration of ultramafic rocks along the slab Moho during the warmest early stages of subduction, and switch to fluids sourced from subducting oceanic crust as the subduction zone matures. In these later, colder stages of subduction, hydrated oceanic mantle will carry mineral-bound $\mathrm{H}_{2} \mathrm{O}$ well past the subarc into the deeper mantle (e.g., Rüpke et al., 2004; Hacker et al., 2008; van Keken et al., 2011). These evolving thermal structures have important implications for fluid sources, global element cycling, and recorded $P-T$ conditions of exhumed subduction-related terranes.

\section{METHOD}

\subsection{Modeling overview}

We use the ASPECT code (version 2.1.0) to construct numerical, time-evolving subduction models within 2-D domains (Kronbichler et al., 2012; Heister et al., 2017; Bangerth et al., 2020a; 2020b). ASPECT was used to solve the conservation equations that govern convection in an incompressible viscous fluid (Boussinesq approximation) with negligible inertia and no internal heating: the conservation of mass (Eq. 1), momentum (Eq. 2), and energy (Eq. 3):

$$
\nabla \cdot v=0
$$

$$
-\nabla \cdot 2 \eta \dot{\varepsilon}+\nabla p=\rho \boldsymbol{g}
$$

$$
\rho C_{p}\left(\frac{\partial T}{\partial t}+\boldsymbol{u} \cdot \nabla T\right)-k \nabla^{2} T=0
$$


136 Where $\boldsymbol{v}$ is velocity, $\eta$ is viscosity, $p$ is pressure, $\rho$ is density, $\boldsymbol{g}$ is gravitational acceleration, $\mathrm{C}_{p}$

137 is the specific heat capacity, $T$ is temperature, and $k$ is the thermal conductivity. $\dot{\varepsilon}$ is the deviatoric

138 strain rate tensor which is $\frac{1}{2}\left(\nabla \boldsymbol{v}+\nabla \boldsymbol{v}^{T}\right)$ for an incompressible fluid.

The models evolve dynamically in that there are no external forces or velocities applied to the subduction system. In this section, we describe the geometrical, mechanical, and rheological properties of our subduction models, with a focus on our reference model (Figs. 1-4). Table 1 provides the parameter values of this model.

Subduction is modeled within a whole mantle domain $(2900 \times 11600 \mathrm{~km})$, where all boundaries are mechanically free slip. We begin our models with two flat laying thermal plates. A 90 Ma, $6000 \mathrm{~km}$ long plate is placed next to a $10 \mathrm{Ma}, 2500 \mathrm{~km}$ long plate and the two plates are separated by a weak crustal layer (Fig. 1a). The older and denser plate bends and subducts beneath the younger plate in a style broadly analogous to intra-oceanic subduction initiation at a transform fault (e.g., Matsumoto and Tomada, 1983).

\subsection{Thermal structure}

The initially flat lying lithospheric plates are defined by half space cooling profiles mantle potential temperature equivalent to that of the GDH1 plate cooling model (Stein and Stein, 1992). Constant temperatures are imposed at the model boundaries $\left(0{ }^{\circ} \mathrm{C}\right.$ surface, 1421.5 ${ }^{\circ} \mathrm{C}$ base and sides). We assume incompressibility in our models and add a $0.3{ }^{\circ} \mathrm{C} / \mathrm{km}$ adiabatic temperature gradient to our modeled temperatures as a post-processing step (e.g., van Keken et al., 2011). Densities are purely temperature dependent and calculated relative to a reference mantle density of $3300 \mathrm{~kg} / \mathrm{m}^{3}$ using a thermal expansion coefficient of $3 \times 10^{-5} \mathrm{~K}^{-1}$.

\subsection{Rheology}

We consider a composite mantle rheology with diffusion creep, dislocation creep, and plastic yielding components. The inclusion of stress-dependent flow (dislocation creep) in the thermal models is important as it elevates slab top temperature (van Keken et al., 2002) and sharpens the down-dip transition from cold to hot forearc material (Wada et al., 2011). In the modeled upper mantle, we use idealized dislocation and diffusion creep flow laws:

$$
\eta_{\text {diff } / \text { disl }}=A^{\frac{-1}{n}} \dot{\varepsilon}^{\frac{1-n}{n}} \exp \left(\frac{E+P V}{n R T}\right)
$$


176 and energies $(E)$ are consistent with the range of experimental values determined for dry olivine

177 (Table 1) (e.g., Karato and Wu, 1993; Hirth and Kohlstedt, 2003). Dislocation and diffusion

178 creep pre-factors are set to give $\eta_{\text {diff }}=\eta_{\text {disl }}=5 \times 10^{20} \mathrm{~Pa} \mathrm{~s}$ at a depth of $330 \mathrm{~km}$ and strain

179 rate of $5 \times 10^{-15} \mathrm{~s}^{-1}$. This produces a reference upper mantle viscosity of $2.5 \times 10^{20} \mathrm{~Pa} \mathrm{~s}$ (Eq. 7)

180 and dislocation creep deformation adjacent to rapidly moving plates and slabs. Dislocation creep

181 occurs to average depths of about $250 \mathrm{~km}$ (Fig. 1b), consistent with the $\sim 100-400 \mathrm{~km}$ inferred

182 from seismic anisotropy studies (e.g., Podolefsky et al. 2004; Becker, 2006). Our lower mantle is

183 more viscous than the upper mantle and deforms via diffusion creep only. The lower mantle

184 diffusion creep pre-factor is calculated to give a lower mantle diffusion creep viscosity 15 times

185 that of the upper mantle diffusion creep viscosity. Due to upper mantle dislocation creep, the

186 effective upper-to-lower mantle viscosity contrast is actually $\approx 30$, in broad agreement with

187 geoid constraints (e.g., Hager, 1984).

We also incorporate a pseudo-plastic component into our effective viscosity, which approximates brittle yielding at lithospheric depths. The plastic viscosity, $\eta_{\text {yield }}$, is computed as:

Where $\tau_{\text {yield }}$ is a Byerlee type yield stress (Byerlee, 1978):

$$
\eta_{y i e l d}=\frac{\min \left(\tau_{\text {yield }}, 0.5 \mathrm{GPa}\right)}{2 \dot{\varepsilon}}
$$

$$
\tau_{y i e l d}=(a P+b) \lambda
$$

$a$ is the friction coefficient $(0.6), \mathrm{b}$ is cohesion (60 MPa), $\mathrm{P}$ is lithostatic pressure, and $\lambda$ is a constant 'pore pressure' factor (0.1), with values comparable to previous subduction modeling studies (e.g., Enns et al., 2005). An effective model viscosity is calculated as:

$$
\eta=\left(\frac{1}{\eta_{\text {diff }}}+\frac{1}{\eta_{\text {disl }}}+\frac{1}{\eta_{\text {yield }}}\right)^{-1}
$$
We use compositional fields to track the location of three regions that are rheologically-distinct from the background material (the slab crust, a strong lithospheric core, and weak regions at the edges of lithospheric plates), with each composition $\left(c_{i}\right)$ advected following:

Weak regions at the edges of the subducting and upper plates are imposed to ensure the initiation of spreading ridges at the start of the model run. These regions are square $\left(75 \mathrm{~km}^{2}\right.$ in size $)$ and have a reduced yield stress $(\lambda=0.025)$. Yielding is switched off within both the overriding plate

$$
\frac{\partial c_{i}}{\partial t}+\boldsymbol{v} \cdot \nabla c_{i}=0
$$
and a $15 \mathrm{~km}$ thick layer in the core of the subducting plate. This is consistent with the presence of a strong core sandwiched between a brittle-yielding upper and ductile-yielding lower 
215 lithosphere (e.g., Karato and $\mathrm{Wu}, 1993)$. The final compositional field corresponds to the weak

216 crust which, as discussed in detail in Section 2.4, is prescribed a constant viscosity. Each

217 compositional field has an equivalent density to the background material (at a given

218 temperature).

The overall model viscosity is capped by upper and lower limits of $2.5 \times 10^{23} \mathrm{~Pa}$ s and 2.5 $\times 10^{18} \mathrm{~Pa}$ s. Due to the strong temperature dependence of the flow laws (Eq. 4), the upper limit sets the strength of our slabs in regions other than where the slab bends and yields. Hence the non-deforming portions of our slabs are $\sim 1000$ times stronger than the surrounding asthenosphere. The yielding region is $\sim 100$ times stronger. Taken together, this produces average slab strengths compatible with the viscosity contrasts of $100-1000$ generally required to satisfy plate bending constraints and produce Earth-like trench motions (e.g., Wu et al., 2008; Funiciello et al., 2008).

\subsection{Decoupling}

In addition to facilitating plate convergence, the weak crust is needed to decouple the slab from the overriding mantle wedge at depths less than about $80 \mathrm{~km}$, and hence generate a cold mantle wedge corner. Low surface heat flow values and petrologically inferred low mantle temperatures at forearcs provide evidence for the occurrence of such a cold mantle wedge corner (Honda, 1985; Furukawa, 1993). In our reference model, the weak crust is initially $10 \mathrm{~km}$ thick, imposed with an initially curved geometry (radius of curvature $=250 \mathrm{~km}$ ), and has a viscosity of $2 \times 10^{20}$ $\mathrm{Pa} \mathrm{s}$, consistent with the experimentally determined basaltic crust viscosities at these conditions (Agard et al., 2016; Behr and Becker, 2018).

By changing the viscosity of the crust in the down-dip direction, or simply cutting the weak crustal layer off, a transition from decoupling at shallow depths (i.e., slab is weaker than overriding wedge corner) to coupling at greater depths (slab stronger than overriding wedge) produces the cold mantle wedge corner region (e.g., Wada et al., 2008; Wada and Wang, 2009). The depth of this transition is often called the "decoupling depth" (DD) and appears to occur across most Earth subduction zones at $\sim 80 \mathrm{~km}$ (Wada and Wang, 2009). Because the DD exerts significant control on slab temperatures (Syracuse et al., 2010; Maunder et al., 2019), we examine three different decoupling parameterizations: shallow crust cut-off, deep crust cut-off, and a visco-plastic crust. In the first two cases, we cut off an isoviscous crust at a specified depth. In the shallow crust case, this cut-off depth is $80 \mathrm{~km}$. In the deep crust case, this cut-off depth is $200 \mathrm{~km}$. Note that this cut-off depth is not necessarily the DD but rather the maximum depth of decoupling (MDD) (cf. Wada and Wang, 2009). This is because the crust can be stronger than the overlying material at depths shallower than the MDD if the overlying wedge is hot and weak, as is the case during most of our modeled subduction. For our reference model, we choose the shallow crust cut-off case following suggestions that MDDs of 70-90 km are required to satisfy surface heat flow measurements (Furukawa, 1993; Wada and Wang, 2009), 
and to render our models comparable to kinematically-driven models that choose a similar depth (e.g., Syracuse et al., 2010; van Keken et al., 2011).

We also test the effect of assigning a stress-dependent rheology to the crust (e.g., Arcay et al., 2007; Arcay, 2012; 2017; Maunder et al., 2018). A visco-plastic rheology is prescribed in the crust with a reduced yield stress pre-factor of $\lambda=0.02$ (Eq. 6). As shown by Maunder et al. (2018), this enables decoupling to emerge without the need to prescribe a cut-off depth. In our models, a yield stress less than or equal to $30 \%$ of the surrounding material, which has $\lambda=0.1$, is sufficient to weaken the segment of crust between the slab and cold wedge corner. We then limit the viscosity using a lower bound that defines the yielded crustal viscosity to be equivalent to that of the isoviscous crust $\left(2 \times 10^{20} \mathrm{~Pa} \mathrm{~s}\right)$. Without this lower bound, the yielded portion of crust becomes very weak which produces unrealistically high convergence rates $(>20 \mathrm{~cm} / \mathrm{yr})$.

\subsection{Numerical parameters}

Adaptive mesh refinement (AMR) is set to occur for finite elements with large gradients in viscosity, temperature, and composition (Fig. 1c, S1). This enables us to highly resolve our 10 $\mathrm{km}$ thick crustal layer material while also capturing flow at the scale of the whole mantle. In addition to the crust, we also highly refine the mesh within the slab core (as is also defined by a compositional field). The AMR parameters in our reference model produce a maximum level of refinement corresponding to $1.4 \mathrm{~km}$ wide finite element dimensions (in the crustal layer), and a minimum level of refinement corresponding to $180 \mathrm{~km}$ finite elements (in the lowermost mantle). Increasing the maximum resolution to the $0.7 \mathrm{~km}$ level does not change model temperature systematics but causes subduction to initiate slightly earlier, by about $0.5 \mathrm{Myr}$ (Figs. S2, S3). We have also conducted numerical accuracy tests to ensure that our linear and nonlinear solver tolerances are sufficiently strict (Fig. S4).

\subsection{Model analysis}

We focus our analysis on the temperatures of the upper (slab top) and lower (slab Moho) surfaces of the subducting crust. To find the location of these two profiles, we first interpolate the crustal compositional field $(0<C<1)$ across the model domain using a cubic interpolation scheme. We then extract pressure and temperature profiles along a contour of $C=0.5$, with contours on either side of the layer corresponding to the slab top and slab Moho. To correct for roughness in the slab top $P$ - $T$ profiles, we smooth the profiles using a Savitzky-Golay filter (cf. Figs. 3 and S5 for smoothed vs. raw profiles). This roughness occurs due to a combination of the strong thermal gradient between the cold slab and hot wedge and our use of rectangular finite elements that are not angled along the slab top. However, this roughness (perturbations of $<\sim 10$ ${ }^{\circ} \mathrm{C}$ ) is minor relative to the temperature variability between analyzed timesteps $\left(\sim 50{ }^{\circ} \mathrm{C}\right)$ (Fig. 
take the additional step of interpolating our $P-T$ profiles using modeled convergence rates (Fig. $2 a$ ). This enables us to capture the time evolution of slab temperature that occurs as a hypothetical rock package descends down the subduction zone.

We next couple these interpolated $P$ - $T$ profiles of the slab top and slab Moho to thermodynamic models of oceanic crust (average Mid Ocean Ridge Basalt [MORB]), and depleted MORB mantle (DMM) to demonstrate how dehydration depths and magnitudes can vary between these two portions of the subducting slab as slab thermal structure evolves. We focus on oceanic lithosphere rather than other lithologies because it has been shown to be the major fluid source in most subduction systems (Schmidt and Poli, 1998; Rüpke et al., 2004; Hacker, 2008; HernándezUribe and Palin, 2019; Condit et al., 2020). Our thermodynamic models were made using the software Perple_X 6.8.3 (Connolly and Petrini, 2002), and use the same solution models and approach as Condit et al. (2020). Details of these models including the bulk compositions used, chemical system, thermodynamic datasets, solution phase models and equations of state are provided in Tables $\mathrm{S} 1$ and S2. Our models encompass $P$ - $T$ conditions ranging from 0.1 to 4.5 $\mathrm{GPa}$ and 200 to $750^{\circ} \mathrm{C}$ (Fig. S6). For simplicity, we assume MORB and DMM are both $\mathrm{H}_{2} \mathrm{O}$ saturated, which is an apt assumption for the fluid-rich plate interface (e.g., Jarrard, 2003; Bebout \& Penniston-Dorland, 2016) and discrete fractures and bending fault zones in mantle lithosphere (e.g., Peacock, 2001; Naif et al., 2015, Grevemeyer et al., 2018). We treat fluids as pure $\mathrm{H}_{2} \mathrm{O}$. Along each of the interpolated slab top and slab Moho $P-T$ paths, we extract the mineral-bound $\mathrm{H}_{2} \mathrm{O}$ remaining in each lithology as they subduct. Together, we use these results to investigate the first order relationship between the evolving thermal structure and patterns of metamorphic $\mathrm{H}_{2} \mathrm{O}$ loss over the lifetime of a subduction zone.

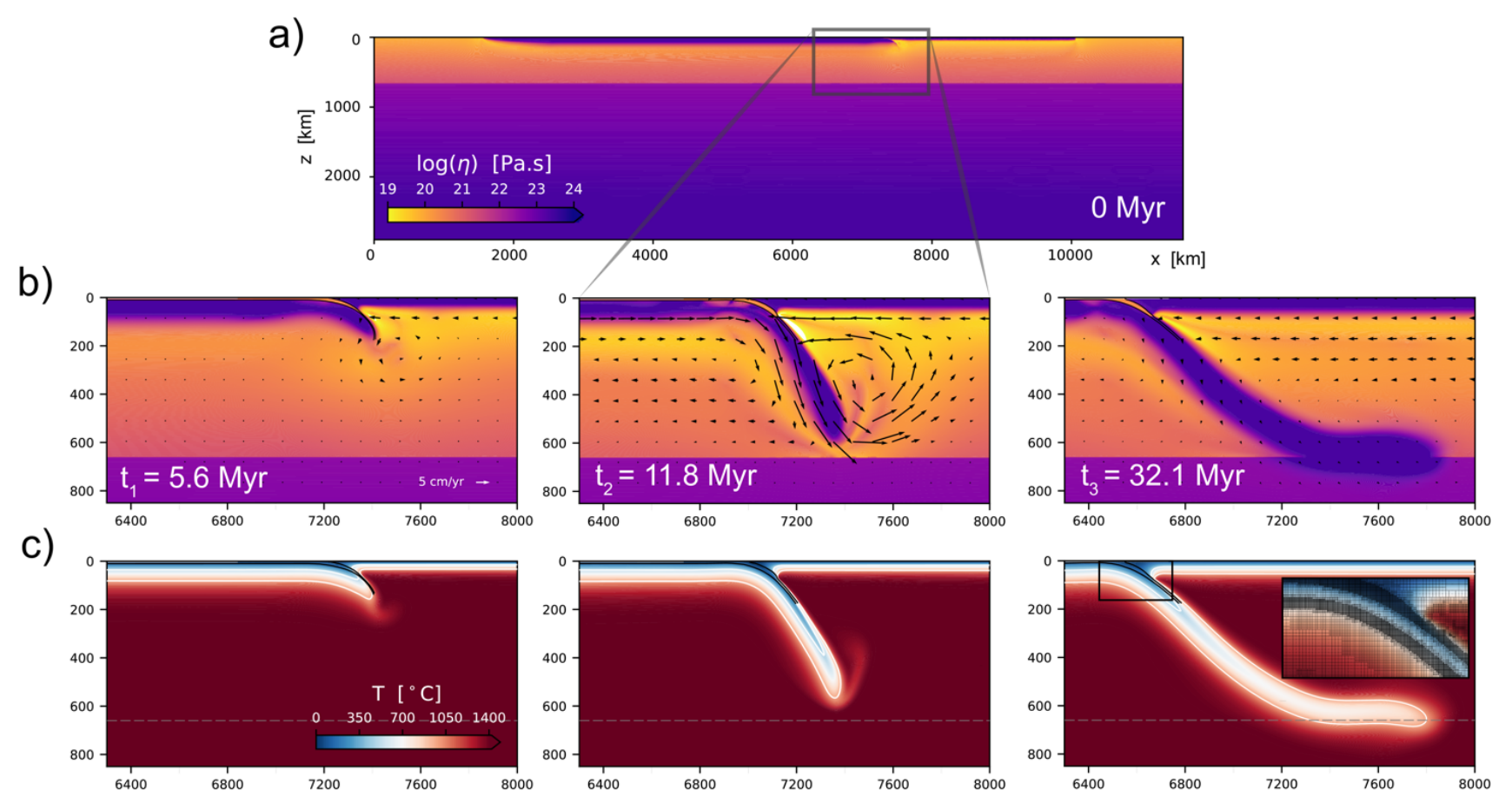


Figure 1: Evolution of the reference model. Panels show: A) the initial viscosity field of the entire model domain, B) evolution of the viscosity and velocity fields zoomed into a region around the subduction zone, C) the temperature field evolution. Three time-steps shown correspond to the initiation $\left(\mathrm{t}_{1}=5.6 \mathrm{Myr}\right)$, free sinking $\left(\mathrm{t}_{2}=\right.$ $11.8 \mathrm{Myr})$, and mature phases $\left(\mathrm{t}_{3}=32.1 \mathrm{Myr}\right)$. Isotherms $\left(500^{\circ} \mathrm{C}, 1000^{\circ} \mathrm{C}\right)$ and the boundaries of the compositional crust are overlain on C. A zoom-in of the computational mesh is overlain on the mature phase of C (note the highly refined crust and slab core regions).

\section{RESULTS}

\subsection{Geodynamic evolution}

We begin by describing the evolution of our reference model (see Table S1 for parameters). by plastic yielding and the initial positioning of the weak crustal channel. At a model time of 5.6 Myr, during this "initiation" phase, the proto-slab has subducted to a depth of $160 \mathrm{~km}$ (Fig. 1) and the convergence rate of the system is $\approx 3 \mathrm{~cm} / \mathrm{yr}$ (Fig. 2a). The subducting plate is approximately stationary and so this convergence rate is a result of trench retreat $\left(v_{T}\right)$ at $\approx 3$ $\mathrm{cm} / \mathrm{yr}$. Subduction initiation over $8 \mathrm{Myr}$ is sluggish but in broad agreement with some geological 331 (Agard et al., 2020) and numerical estimates (Dymkova and Gerya, 2013).

a)

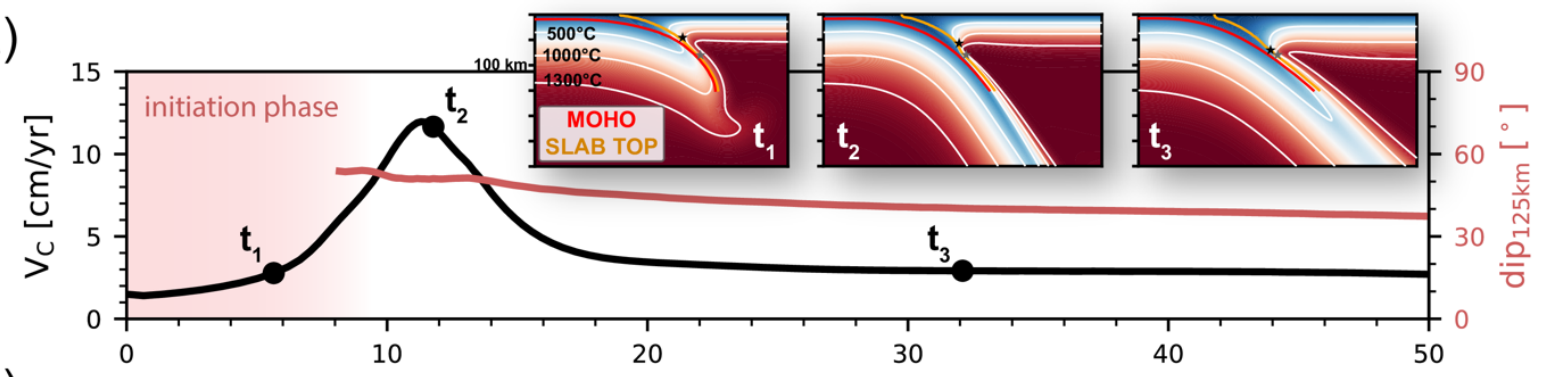

b)

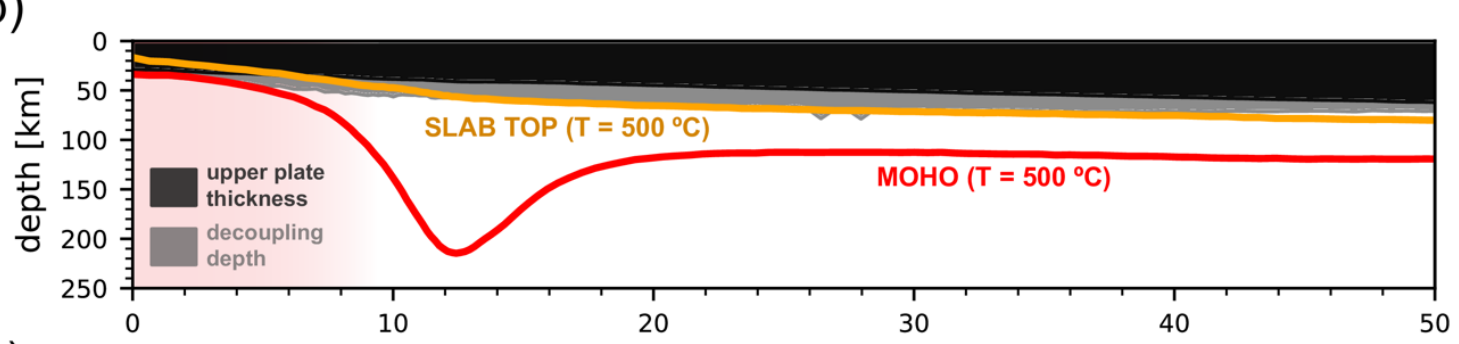

c)

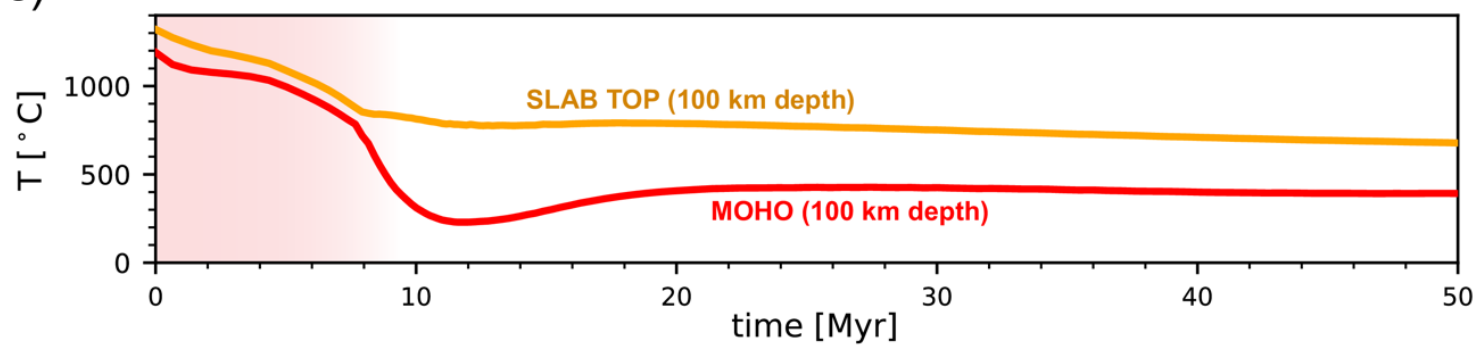

Figure 2: Temporal evolution of subduction properties. A) Subduction zone convergence rate and shallow slab dip (at depth $=125 \mathrm{~km}), \mathrm{B}$ ) the depth of the $500{ }^{\circ} \mathrm{C}$ isotherm along the slab top and slab Moho and upper plate thickness 
and decoupling depth, C) the temperature at a depth of $100 \mathrm{~km}$. Also, in A): Zoomed in snapshots of thermal structure for the three times shown in Figure $1\left(t_{1}, t_{2}, t_{3}\right)$ with slab Moho and slab top locations, the decoupling depth (black star), and maximum depth of decoupling ( $80 \mathrm{~km}$, grey star).

332

333

334

335

As the slab subducts deeper, and the total negative buoyancy increases, the convergence rate increases during the "free-sinking" phase (i.e., slab sinking through the upper mantle). Convergence rates are maximum during this phase as the excess bending resistance to subduction initiation has been overcome, while the slab has not yet reached the high viscosity lower mantle. As seen in previous dynamic models (e.g., Holt and Becker, 2017), this pulse of rapid plate convergence is enhanced by a reduction in viscous resistance in the upper mantle that occurs due to wide-spread activation of dislocation creep (Figs. 1b, 2a). Our second snapshot is at a model time of $11.8 \mathrm{Myr}$, where the $\approx 12 \mathrm{~cm} / \mathrm{yr}$ convergence rate is near the model's maximum value and the slab dip is $\approx 50^{\circ}$ at shallow depths ( $125 \mathrm{~km}$ depth). The $12 \mathrm{~cm} / \mathrm{yr}$ convergence rate is partitioned between a subducting plate velocity $\left(v_{S P}\right)$ of $\approx 7 \mathrm{~cm} / \mathrm{yr}$ and $v_{T}$ of $\approx 5 \mathrm{~cm} / \mathrm{yr}$. The initially uniformly thick $(10 \mathrm{~km})$ crust gradually thickens to $\approx 15 \mathrm{~km}$ as it descends into the trench. This is because slab rollback induces horizontal extension in the crust at upper plate depths which, in turn, thickens it locally within this region (cf., Holt et al., 2017; Sandiford and Moresi, 2019; Beall et al., 2021).

The final, "mature" phase begins as the slab impinges on the lower mantle at a depth of $660 \mathrm{~km}$. The viscous resistance of the strong lower mantle slows subduction to convergence rates of $\approx 3$ $\mathrm{cm} / \mathrm{yr}\left(v_{S P} \approx 1 \mathrm{~cm} / \mathrm{yr}, v_{T} \approx 2 \mathrm{~cm} / \mathrm{yr}\right)$ (Fig. 2a). Simultaneously, the slab leans back as $v_{T}$ exceeds $v_{S P}$ and slab evolution reaches a near-steady state with near-constant convergence rates. The dislocation creep prevalent in the previous phase is now more localized due to reduced asthenospheric strain rates. Our third snapshot is at a model time of 32.1 Myr within this phase. During the very lattermost stages of the model ( $>65 \mathrm{Myr}$ ), this near-steady state configuration is disrupted when the strong, sub-crustal portion of the slab comes into contact with the overlying fore-arc. This causes the convergence rate to further drop to $\approx 1.5 \mathrm{~cm} / \mathrm{yr}$.

\subsection{Thermal evolution}

We focus our analysis of the thermal evolution of the reference model on the temperatures at the base (slab Moho) and upper surface (slab top) of the crust. At a given pressure, these two temperatures bracket those that exhumed crustal rocks would be expected to experience. During the subduction initiation phase, low convergence rates are accompanied by high slab Moho and slab top temperatures. During the initiation snapshot $(t=5.6 \mathrm{Myr})$, temperatures of $500{ }^{\circ} \mathrm{C}$ reach depths as shallow as $\approx 52 \mathrm{~km}(1.7 \mathrm{GPa})$ along the slab Moho and $\approx 33 \mathrm{~km}$ (1 GPa) along the slab top (Fig. 2b). Such warm temperatures are consistent with petrologic observations of warm conditions during the early stages of subduction (e.g., Platt, 1975; Cloos, 1985; Agard et al., 2018). 
369 Rapid cooling of both the slab Moho and slab top occur during the initiation phase, over $\sim 8$

370 Myr, after which more protracted cooling persists for the rest of the model evolution.

371 Considering the slab top at a depth of $100 \mathrm{~km}$, cooling of $\approx 55^{\circ} \mathrm{C} / \mathrm{Myr}$ occurs for the first $8 \mathrm{Myr}$.

372 After which, cooling is at the much lower rate of $\approx 5^{\circ} \mathrm{C} / \mathrm{Myr}$ (Fig. 2c). This can also be seen by

373 the gradual increase in depth of slab top isotherms throughout the $50 \mathrm{Myr}$ of slab evolution (Fig

$3742 \mathrm{~b}$ ). From an initial depth of $\approx 17 \mathrm{~km}$, the $500{ }^{\circ} \mathrm{C}$ isotherm reaches a depth of $\approx 72 \mathrm{~km}$ by the

375 time of our mature subduction snapshot (32.1 Myr).

This slab top temperature decrease can be linked to evolution of the thermal structure directly overlying the slab which is, in turn, manifested in the upper plate thickness $\left(h_{O P}\right)$ and decoupling depth (DD). As described the Section 2.4, the slab and wedge are decoupled at shallow depths which causes a cold wedge corner to develop above the slab at depths $<$ DD. We do not impose the DD in our models but track an equivalent depth that emerges self-consistently. Our DD is taken to be where the mantle overlying our crust transitions down-dip from cold and strong $(\eta>$ $\left.2.5 \times 10^{22} \mathrm{~Pa} \mathrm{~s}\right)$ to hot and weak material $\left(\eta \leq 2.5 \times 10^{22} \mathrm{~Pa} \mathrm{~s}\right)$. The DD increases through time, in part due to a gradual increase in $h_{O P}$ (due to thermal thickening), until it approaches the imposed maximum depth of decoupling $(\mathrm{MDD}=80 \mathrm{~km})$ during the mature subduction phase (Fig. 2b). From then, it becomes approximately constant at $\sim 75 \mathrm{~km}$ (until the very end of the model, $\mathrm{t}>>60 \mathrm{Myr}$, when slab-forearc collision occurs). Cooling of the shallow portion of the slab top (i.e., slab top adjacent to the cold wedge corner) is caused by the thickening of this cold forearc region that occurs with increasing DD and $h_{O P}$. The DD and $h_{O P}$ control on slab top cooling is illustrated by the correspondence of the $500^{\circ} \mathrm{C}$ slab top isotherm depth with the DD (Fig. 2b), and that of the shallower, $200^{\circ} \mathrm{C}$ slab top isotherm with $h_{O P}$ (Fig. S7).
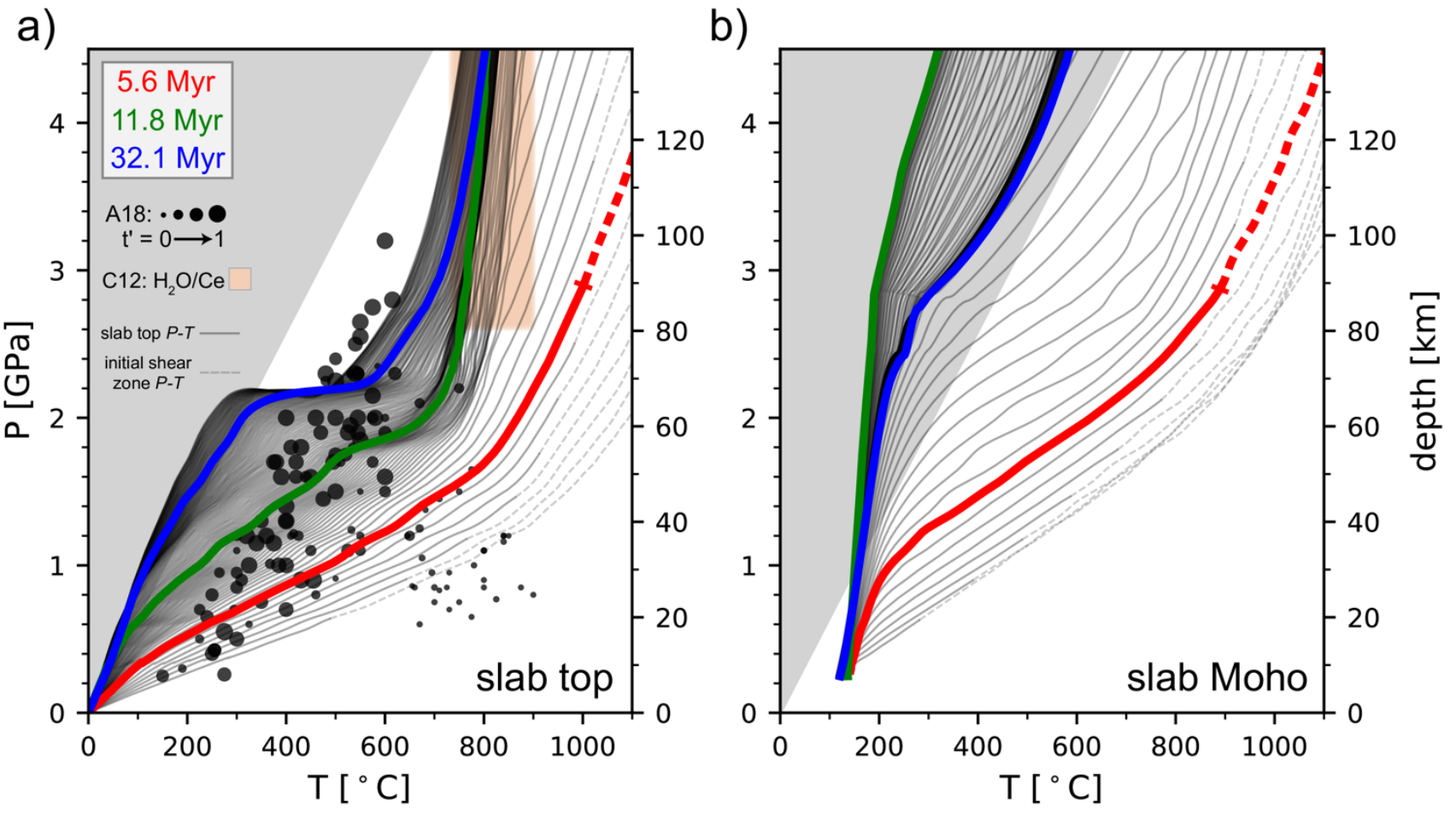
Figure 3: Temporal evolution of $P-T$ conditions along: A) the slab top, B) the slab Moho. Profiles from the three representative times are highlighted (cf. Fig. 1). In addition to lithostatic pressure, dynamic pressure due to viscous flow is included in the plotted pressure. Agard et al's (2018) compilation of the $P$ - $T$ conditions recorded by rocks exhumed at oceanic subduction zones (point size represents the sample time relative to the lifetime of the corresponding subduction zone) and Cooper et al's (2012) global range of sub-arc slab top temperatures (estimated using the $\mathrm{H}_{2} \mathrm{O} / \mathrm{Ce}$ thermometer on melt inclusions) are included in A. The gray region corresponds to average $\mathrm{dT} / \mathrm{dz}$ $<5^{\circ} \mathrm{C} / \mathrm{km}$, i.e., the forbidden zone not represented in the exhumed rock record. These $P-T$ profiles have been smoothed (see Fig. S4 for equivalent raw profiles) and the total model-time plotted is $52 \mathrm{Myr}$. We dash profiles at depths greater than that which an initially flat-lying crust would reach (i.e., dashed portions represent the initial lithospheric shear zone).

Inspecting pressure-temperature $(P-T)$ profiles extracted from the slab top (Fig. 3a), cooling is demonstrated by the transition between hot $P-T$ profiles during the initiation phase, intermediate $P-T$ profiles during free-sinking, and cold $P-T$ profiles during the mature phase. This causes the $P-T$ profiles to sweep through a significant proportion of the $P-T$ space associated with Agard et al's (2018) oceanic subduction exhumed rock compilation. All $P$ - $T$ profiles exhibit increasing temperature with depth, with higher thermal gradients at shallower depths that transition into lower thermal gradients in the deeper mantle wedge. During the intermediate free sinking phase, for example, $d T / d z$ is $\sim 12{ }^{\circ} \mathrm{C} / \mathrm{km}$ at depths less than $70 \mathrm{~km}$. Deeper, $d T / d z$ transitions to less than $5{ }^{\circ} \mathrm{C} / \mathrm{km}$. This kink occurs at a depth similar to the DD and becomes very pronounced as the DD approaches the MDD during mature subduction (Fig. 3a). This kinked $P-T$ profile shape is consistent with that observed in kinematically-driven thermal models with imposed DD (e.g., Syracuse et al., 2010; van Keken et al., 2011). We also calculate the depth that the initially flatlying portion of the crust would reach during each model time-step and dash our $P$ - $T$ profiles at depths beyond this (Fig. 3). This is important during the earliest subduction stages, where the portion of the crust that was initially flat lying is shallower than the deepest compositional material of the weak interface. This is because this material is also used to define the initial lithospheric shear zone that facilitates subduction initiation (Fig. 1a).

The slab Moho temperature exhibits a more complex evolution. After rapid cooling during subduction initiation, the Moho experiences additional cooling whilst the slab sinks rapidly through the upper mantle during the free-sinking phase (Fig. 2). This free-sinking thermal transient spans 5 to $10 \mathrm{Myr}$ and is more pronounced at greater depth (i.e., for higher slab Moho temperatures: Fig. S7). Slab Moho temperatures of $500^{\circ} \mathrm{C}$, for example, are dragged down to depths of $215 \mathrm{~km}$ during this phase, which is $\sim 100 \mathrm{~km}$ greater than the background cooling trend (Fig. 2b). This cooling phase ends as the slab hits the upper-to-lower mantle viscosity jump and the slab Moho temperatures increase in response to a rapid decrease in convergence rate. $P-T$ profiles extracted along the slab Moho show this transient as rapid steepening of $P-T$ profiles to cold conditions during the free sinking phase (green profile; Fig. 3b) before rebounding to warmer conditions (blue profile; Fig. 3b). For much of the model evolution, we note that slab Moho $P$ - $T$ profiles reside within the "forbidden zone" $\left(\mathrm{dT} / \mathrm{dz}<5{ }^{\circ} \mathrm{C} / \mathrm{km}\right)$ that is not represented in the exhumed rock record. This is due to a combination of our old subducting plate age and 
relatively high crustal thickness (initially $10 \mathrm{~km}$ but, in places, increasing to $\approx 15 \mathrm{~km}$ due to crustal thickening within the down-going slab).

\subsection{Dehydration evolution}

Coupling interpolated slab top and slab Moho $P-T$ paths with thermodynamic models of MORB and DMM reveal differences in dehydration evolution over the lifetime of a subduction zone (Fig. 4). This is due to a combination of the different $P-T$ paths a package of rock takes along the slab top versus the slab Moho (Fig. 3) and the stability of hydrous minerals within MORB and DMM across time varying $P-T$ conditions (Fig. S6). At the slab top, fluid saturated MORB dehydrates at shallower depths than DMM along the slab Moho for any given time step, and the two lithologies and thermal paths yield different locations and magnitudes of dehydration at various stages of subduction.

At the slab top, during the initiation phase of subduction, MORB releases $\mathrm{H}_{2} \mathrm{O}$ in several large pulses $(\sim 1-2 \mathrm{wt} \%)$ at shallow forarc depths $(>40 \mathrm{~km})$ due to the relatively high geothermal gradient (Fig. 4a). As the subduction zone speeds up and cools during the free-sinking phase, dehydration depths increase, and multiple discrete dehydration pulses are transformed into a single large $\sim 3.5-4.5 \mathrm{wt} \%$ release of $\mathrm{H}_{2} \mathrm{O}$ corresponding to the blueschist to eclogite transition at depths of $\sim 60$ to $75 \mathrm{~km}$ (Fig. 4a; S6a). As the subduction zone reaches its mature phase, and the slab begins to interact with the lower mantle (and the slab top cools further), dehydration from MORB at the slab top occurs at depths of 75 to $90 \mathrm{~km}$ releasing $\sim 5 \mathrm{wt} \% \mathrm{H}_{2} \mathrm{O}$ over a narrow depth range into the subarc mantle (Fig. 4a).

Along the slab Moho, during the initiation phase (red line in Fig. 4b), $\mathrm{H}_{2} \mathrm{O}$ saturated DMM releases $\mathrm{H}_{2} \mathrm{O}$ in a gradual pulse of $\sim 1.0 \mathrm{wt} \%$ at shallow depths from 40 to $60 \mathrm{~km}$. This is followed by major dehydration of $7.5 \mathrm{wt} \% \mathrm{H}_{2} \mathrm{O}$ at depths of $65-90 \mathrm{~km}$. The largest dehydration reaction represents the breakdown of serpentine (antigorite) and transformation of this phase into olivine (Fig. S6b). The depths of each pulse of dehydration become progressively deeper with increasing subduction age until at $\sim 8 \mathrm{Myr}$ when DMM remains hydrated past the range of our thermodynamic models and brings $\sim 10 \mathrm{wt} \% \mathrm{H}_{2} \mathrm{O}$ deeper than $4.5 \mathrm{GPa}(>150 \mathrm{~km})$. This implies that, if the slab mantle is fully hydrated fully in some places, for example along bending faults formed near the trench (e.g., Grevemeyer et al., 2018), vast quantities of water are transported past the subarc into the deeper portions of the mantle during intermediate and mature phases of subduction. 
A
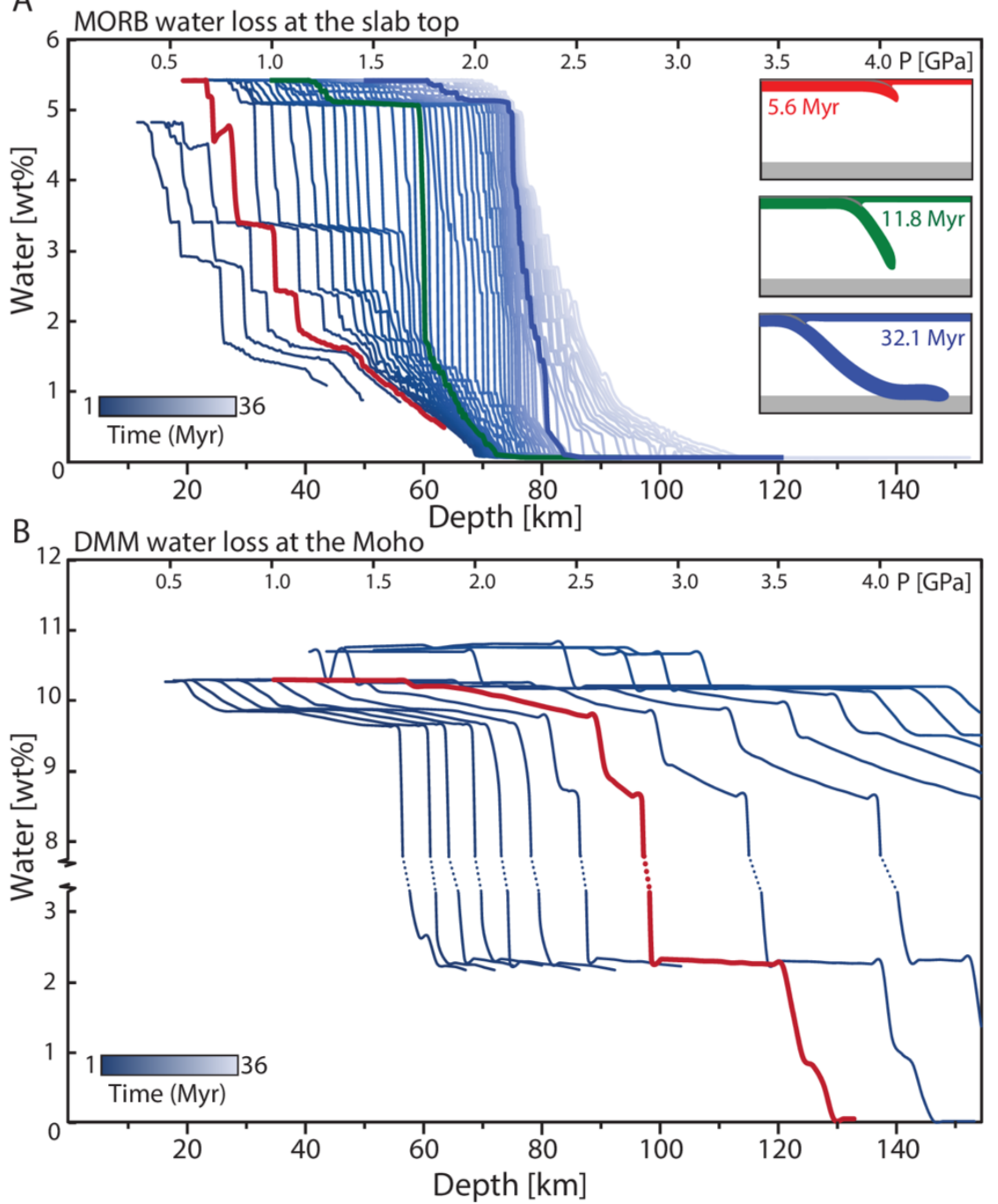

Figure 4: Dehydration during subduction shown as mineral bound $\mathrm{H}_{2} \mathrm{O}$ (wt\%) versus depth and pressure. A) MORB mineral bound water evolution along the evolving slab top. Each line represents slab top MORB $\mathrm{H}_{2} \mathrm{O}$ loss at time slices of $\sim 1$ Myr intervals (every 100 model timesteps) starting at the left at 0.6 Myr. The bold colored lines represent mineral bound $\mathrm{H}_{2} \mathrm{O}$ at each of the three subduction stages in the inset corresponding to each color. B) DMM mineral bound $\mathrm{H}_{2} \mathrm{O}$ across the evolving slab Moho. Each line represents mantle lithosphere water loss at times slices of $\sim 0.5 \mathrm{Myr}$ intervals (every 50 timesteps) starting at the left at $0.6 \mathrm{Myr}$. Note after $\approx 10 \mathrm{Myrs}$ DMM $\mathrm{H}_{2} \mathrm{O}$ loss at the slab Moho is no longer resolved in the thermodynamic P-T model space.

Our analysis complements previous work on slab dehydration (e.g., Hacker et al., 2008; van Keken et al., 2011; Rüpke et al., 2004, Abers et al., 2017) by demonstrating that variable dehydration patterns are associated with a thermal structure that evolves in a dynamically consistent fashion. It is also important to note that while we extract mineral bound $\mathrm{H}_{2} \mathrm{O}$ along the slab top (Fig. 4a) and slab Moho P-T paths (Fig. 4b), the core of the slab crust will have a thermal structure that is in between these two paths, while the core of the subducting oceanic lithosphere will be colder than the slab Moho. Thus, dehydration from slab crust core and mantle core will occur at slightly different depths, ultimately resulting in a smearing out of dehydration loci between these two end members. 


\subsection{Variable subduction parameters}

We now examine the effects of additional subduction properties. This is to explore whether our reference model is representative of a broader subduction zone parameter space, and to develop

472 further intuition about links between time-dependent thermal structure and slab evolution. Figure

4735 show the thermal evolution as a function of three subduction properties that are relatively

474 uncertain and/or may vary substantially in nature: slab, crust, and lower mantle viscosity. To investigate these properties, we focus on the slab Moho and slab top temperatures at relatively shallow depths $(60 \mathrm{~km}$ and $100 \mathrm{~km})$ and examine how the dependence of such temperatures on physical subduction parameters vary relative to the reference (black profile in each panel of

478 Figure 5).

a)

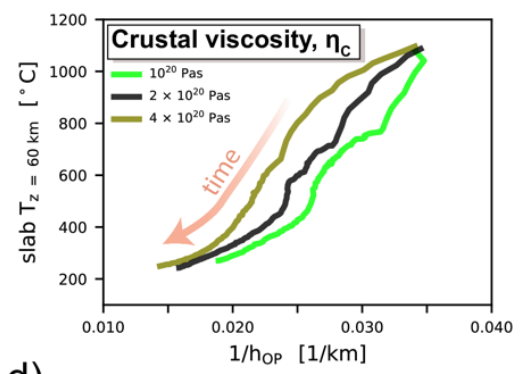

d)

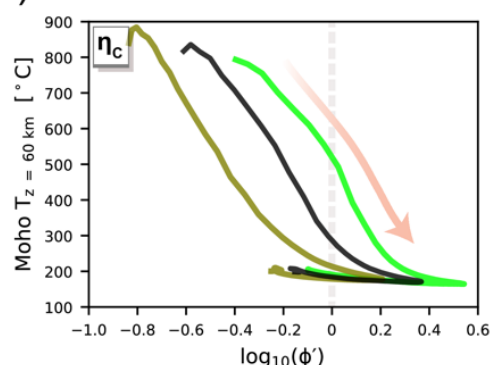

g)

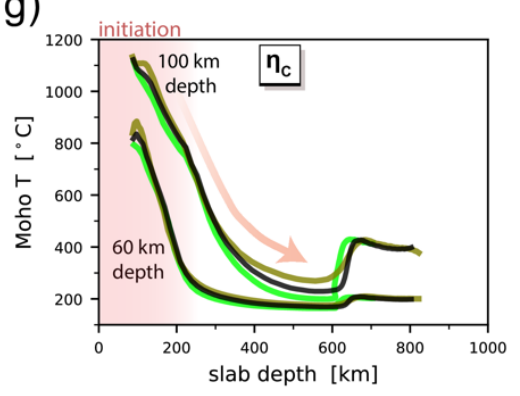

b)

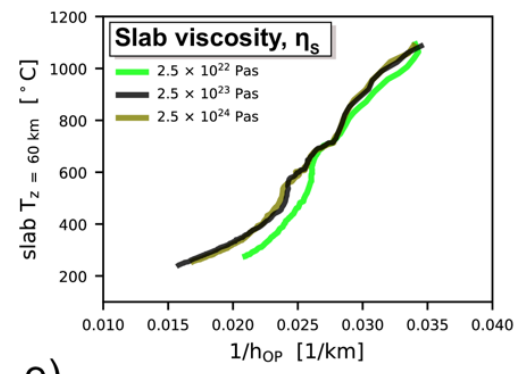

e)

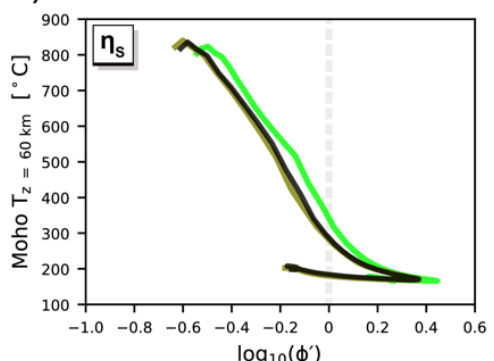

h)

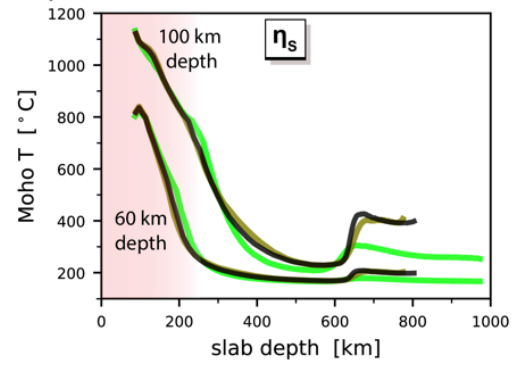

c)

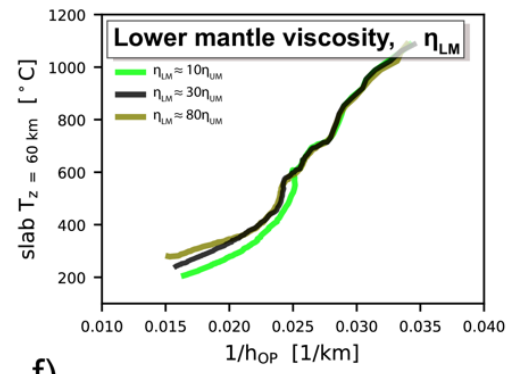

f)

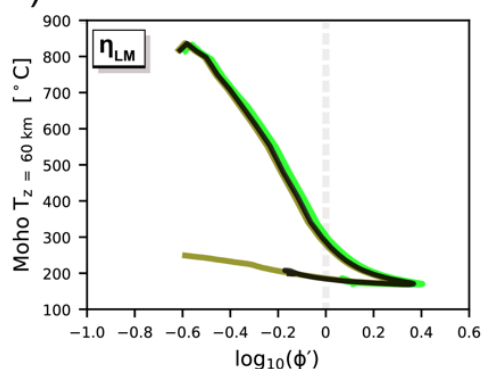

i)

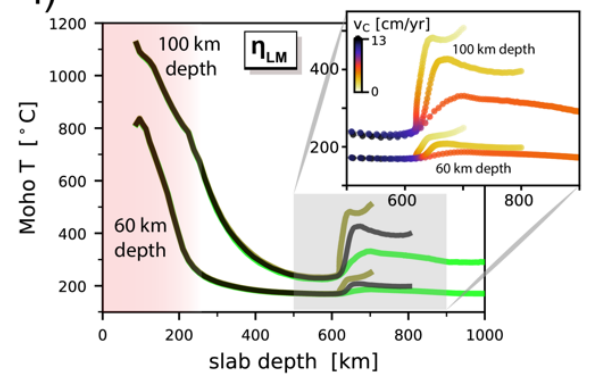

Figure 5: Subduction zone temperature as a function of kinematic subduction properties for variable model parameters. Models have variable crust viscosity, slab viscosity, and lower mantle viscosities, with the reference model plotted in black. A-C) Slab top temperature (depth $=60 \mathrm{~km})$ as a function of the reciprocal of upper plate 
thickness, D-F) slab Moho temperature (depth $=60 \mathrm{~km}$ ) as a function of the logarithm of the (normalized) thermal parameter and G-I) slab Moho temperature (depths $=60 \mathrm{~km}, 100 \mathrm{~km}$ ) as a function of slab depth. The thermal parameter is normalized by its value at $v_{C}=5 \mathrm{~cm} / \mathrm{yr}$ and $t=100 \mathrm{Ma}$ (i.e., $\phi_{0}=5000 \mathrm{~km}$ ). Panel I) includes a zoom in corresponding to when the slab interacts with the viscous lower mantle (points colored by convergence rate). Note that time-dependent dislocation creep produces a time-dependent upper-to-lower mantle viscosity ratio; the quoted values $(10,30,80)$ are averaged over the mature phase of subduction.

As in the reference case, slab top temperature exhibits a strong dependence on the overriding plate thickness $\left(h_{O P}\right)$, and interrelated DD, within all models. To first order, the inverse relationship between slab top temperature and $h_{O P}$ is approximately linear (Fig. 5a-c). On top of this relationship is, in some cases, a shift related to convergence rate $\left(v_{C}\right)$. High convergence rates transport cold surface temperatures down to the depth of interest more rapidly, thereby producing colder slab top temperatures for a given $h_{O P}$. Models with either weak crusts (Fig. 5a) or weak slabs (Figs. 5b, S8) exhibit faster convergence and hence cooler slab tops. A weaker lower mantle also produces faster convergence, and cooler slab tops, but only during the mature subduction phase (Figs. 5c, S9).

In all models, slab Moho temperature exhibits a negative correlation with the "thermal parameter" $(\phi)$ (Kirby, 1996), here taken as the product of plate age $(t)$ and convergence rate $\left(v_{C}\right)$. We normalize the thermal parameter by a reference value (at $v_{C}=5 \mathrm{~cm} / \mathrm{yr}, t=100 \mathrm{Ma}$ ) and examine how slab Moho temperature varies as a function $\log _{10}\left(\phi^{\prime}\right)$ (Fig. 5d-f). The logarithm of $\phi^{\prime}$ is plotted following kinematically-driven models within which slab temperature exhibits a linear correlation with $\log (\phi)$ (van Keken et al., 2011). In all of our models, slab Moho temperature decreases as $\phi^{\prime}$ increases $\left(v_{C}\right.$ increases) rapidly during subduction initiation and free-sinking (Fig. 5d-f). As the slab begins to feel the effects of the strong lower mantle, and $v_{C}$ decreases, the strength of the dependence of Moho temperature on $\phi^{\prime}$ reduces significantly. That is, while $\phi^{\prime}$, or $\log _{10}\left(\phi^{\prime}\right)$, decreases rapidly due to this $v_{C}$ decrease, the Moho temperature does not increase to the extent expected from the trend of the previous subduction phases. This is due to thermal thickening of the upper plate and the associated increase in the decoupling depth (DD). As the DD approaches, and then exceeds, where slab Moho temperature is extracted (60 $\mathrm{km}$ depth), the conductive heating of the slab Moho region, and hence the slab Moho temperature, decreases. The subsequent reduction in the strength of slab Moho temperature dependence on $v_{C}$ is in line with Maunder et al.'s (2019) suggestion that temperatures within different regions of the slab exhibit differing dependencies on $v_{C}$. Particularly, that crustal temperatures at depths $<<$ DD become largely independent of $v_{C}$ (i.e., they are dominantly plate age, $t$, controlled). This illustrates the importance of non-steady state thermal structure inherited from previous subduction phases. For models with varying $v_{C}$, a shift to higher Moho temperatures occurs for higher $v_{C}$ (e.g., Fig. $5 \mathrm{~d}$ ). This stems from the model initial conditions, where temperature is prescribed (i.e., constant) but $\phi^{\prime}$ is calculated dynamically (i.e., variable $v_{C}$ produces variable $\left.\phi^{\prime}\right)$. 
513 All slab Moho temperatures reduce during the free-sinking phase and then increase following the $v_{C}$ reduction as the slab hits the strong lower mantle (Fig. 5g-i). Slab Moho temperatures during the free-sinking phase are lowest for the fastest subduction zones (e.g., weak slab or weak crust) and, upon slab interaction with the lower mantle, the temperature increase is greatest for subduction zones with the largest $v_{C}$ reduction (e.g., models with a strong lower mantle: Fig. 5i).

\subsection{Variable decoupling parameterization}

We now examine the effect of variable crustal decoupling parameterizations on slab thermal structure. These tests are motivated by considerable uncertainty regarding the physical mechanism responsible for the down-dip decoupling-to-coupling transition. In addition to cutting off the isoviscous crust at $80 \mathrm{~km}$ (i.e., our reference model), we examine cases where the crust is cutoff at a greater depth $(200 \mathrm{~km})$ and where the crust has a visco-plastic rheology. As detailed in Section 2.4, the low plastic yield stress of the visco-plastic crust is one mechanism to selfconsistently mimic a transition from shallow decoupling to deep coupling in numerical models (Figs. 6c, S10, Maunder et al., 2018). The three parameterizations produce similar slab top $P-T$ profiles during the initiation and free sinking phases (Fig. 6). This follows from the nearly equivalent DDs that emerge during these earlier phases (e.g., $\approx 60 \mathrm{~km}$ during free sinking). The precise timing of the various phases is the only minor source of variability. In the visco-plastic crust case, subduction initiation is about 2 Myr slower which causes these thermal phases to occur 2 Myr later than in the isoviscous crust cases (Fig. S11).

a) Shallow crust (reference)

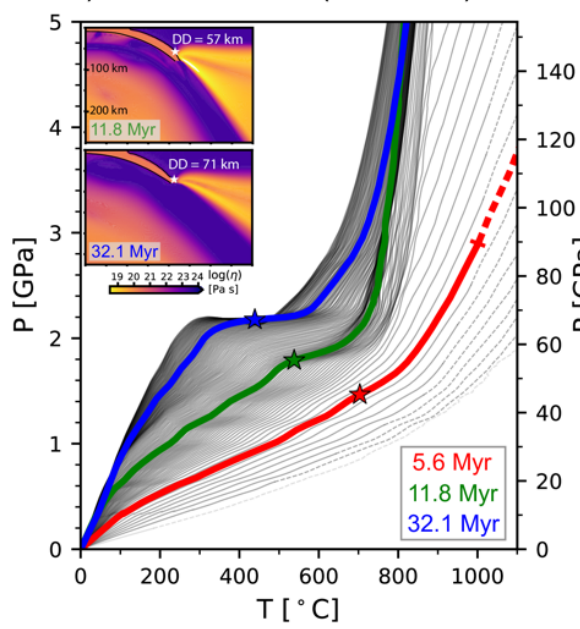

b) Deep crust

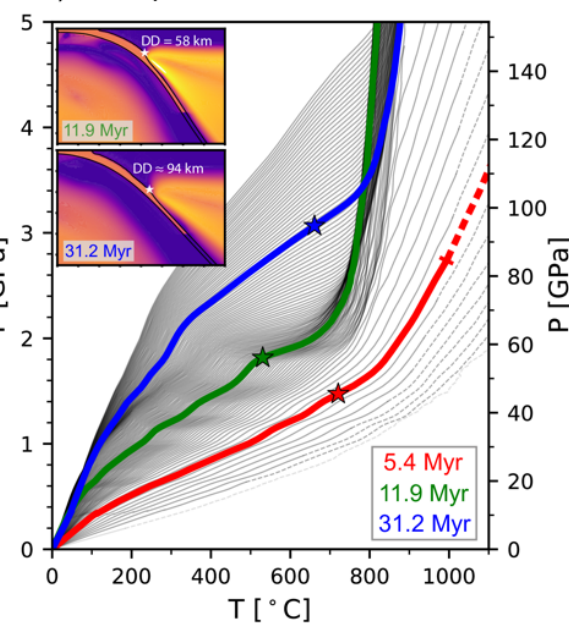

c) Visco-plastic crust

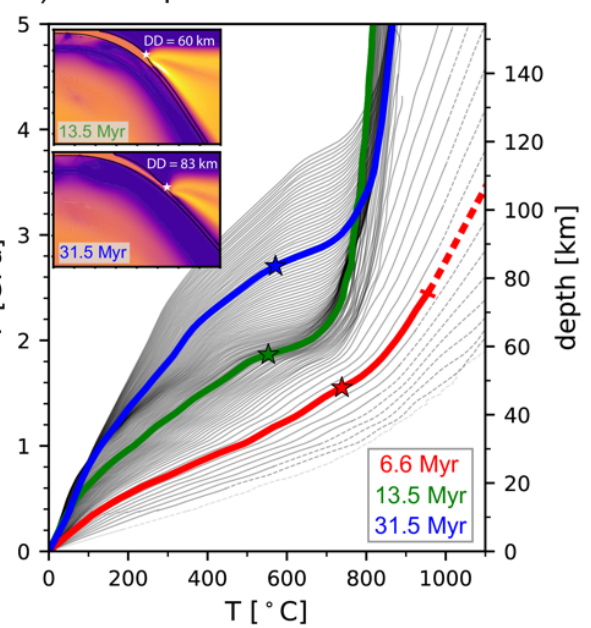

Figure 6: Comparison of slab top pressure-temperature evolution for variable crustal parameterizations: A) Isoviscous crust cut-off at $80 \mathrm{~km}$ depth (reference model), B) isoviscous crust cut-off at $200 \mathrm{~km} \mathrm{depth,} \mathrm{C)} \mathrm{visco-}$ plastic crust. Insets show viscosity structure zoomed into the trench region during free sinking (green) and mature phases (blue). Overlain are the decoupling depths calculated as described in Section 3.2. For all models, P-T profiles are plotted for between 52 and 54 Myrs of subduction evolution. 
535 More significant variability occurs during the mature phase of subduction, during which the DD

536 varies significantly between parameterizations. After $\approx 40 \mathrm{Myr}$ of evolution and upper plate

537 thickening, the DD in the shallow crust cutoff case reaches a near constant $\approx 75 \mathrm{~km}$ (as the DD

538 approaches the imposed maximum depth of decoupling of $80 \mathrm{~km}$ ). In contrast, in the other two

539 cases, the DD continues to increase during the mature phase. This increase in DD corresponds to

540 thickening of the cold mantle wedge corner which produces continuously cooling slab tops in

541 these two models (Fig. 6b,c). DD increase is most rapid in the deep crust cutoff model, relative

542 to the visco-plastic case, which is reflected in more rapid slab top cooling (Fig. S11). This

543 contrasts with the thermal conditions reached during the mature phase of the reference case

544 which exhibit only very minor slab top cooling (Fig. 6a). The evolution of slab Moho $P-T$

545 conditions follows a comparable trend. While all $P-T$ profiles are comparable before $\sim 30 \mathrm{Myr}$,

546 the two additional tests exhibit significant slab Moho cooling after this time while the shallow

547 crust cutoff case does not (Fig. S12).

\section{DISCUSSION}

\subsection{Dynamically evolving thermal structure}

Previous studies have mapped out the dependence of subduction zone thermal structure on subduction parameters using models of mantle wedge flow driven by imposed subduction velocity, slab dip, and overriding plate thermal structure (e.g., Wada and Wang, 2009; Syracuse et al., 2010). Time-dependent thermal structure can be introduced within this type of kinematically-driven modeling approach by imposing time-varying slab properties and/or inspecting thermal evolution prior to steady-state/quasi steady-state (e.g., Peacock and Wang, 1999; Hall, 2012; van Keken et al., 2018; Suenaga et al., 2019). However, such approaches are unable to ensure that the slab, plates, and mantle wedge co-evolve in a dynamically consistent manner, and in the case of steady-state models, resolve transient thermal effects. Motivated by this, we have used dynamically consistent subduction models to probe the co-evolution of subduction zone properties and slab thermal structure. Our modeling approach has similarities to that of Arcay $(2012 ; 2017)$ and Kincaid and Sacks (1997), in that we investigate time-dependent thermal structure in models that solve for thermo-mechanical deformation in a region extending beyond the mantle wedge and, as in Kincaid and Sacks (1997), we do not impose plate velocities. Kincaid and Sacks (1997) demonstrate that significant slab top temperature variability can occur through time in their numerical models. Driven by dynamic variability in subduction parameters like convergence rate (e.g., Clark et al., 2008; Cerpa et al., 2014), we also observe a strong time dependence of modeled slab pressure-temperature $(P-T)$ conditions. By expanding these modeling studies to a large model domain, with self-consistently evolving trenches and crustal geometries, we are able to further elucidate the links between mantle-scale subduction 
575 The links between slab temperature and subduction kinematics in our models are in general

576 agreement with previous studies. The primary control on slab Moho temperature is convergence

577 rate, as has been demonstrated extensively within kinematically-driven thermal models (e.g.,

578 Peacock, 1991; Peacock and Wang, 1999; Van Keken et al., 2002). When coupled with a

579 dynamically evolving slab, this results in a pulse of the coldest slab Moho temperatures during

580 the "free-sinking" phase of subduction: i.e., the fastest subduction phase before the slab impinges

581 on the lower mantle. In addition to the time dependence of subduction parameters, non-steady

582 thermal structure from previous subduction phases impacts slab temperatures at any given time.

583 For example, the convergence rate begins to decrease after about $11 \mathrm{Myr}$ of model evolution and,

584 during the mature phase, has reduced to the few $\mathrm{cms} / \mathrm{yr}$ observed during the initiation phase. As

585 expected, the slab Moho temperature increases as the convergence rate decreases. However, this

586 occurs by $>>100^{\circ} \mathrm{C}$ less than that expected following a basic scaling with the thermal parameter

587 (Fig. 5d-f). This is likely due to the gradual development of a larger cold wedge corner, as the

588 upper plate ages and thickens, which overlies the slab at shallow depths. This reduces slab Moho

589 temperatures below those expected from a basic scaling with a modified form of the thermal

590 parameter. This illustrates the importance of non-steady state subduction zone thermal structure.

$P-T$ conditions along the slab top are primarily controlled by the depth extent of this cold wedge corner region that overlies the slab. As the modeled overriding plate ages, and its thickness and decoupling depth (DD) increases, the enlarging of the cold wedge corner produces slab top cooling. While such a dependence of slab top $P-T$ on DD has been shown in kinematicallydriven models (Syracuse et al., 2010; Maunder et al., 2019; Perrin et al., 2018), an important distinction is that our DD evolves in a dynamically consistent manner. The DD, which marks the down-dip transition from cold/strong to hot/weak wedge material, exhibits significant variation throughout the model evolution (Fig 6a). While this appears at odds with previous suggestions of a near-uniform DD ( $\sim 80 \mathrm{~km})$, based on surface heat flow measurements and first-order petrological constraints (Tatsumi, 1986; Furukawa, 1993; Wada and Wang, 2009), we note that any global survey of present-day subduction zones is naturally skewed away from the initial subduction phases that exhibit the most DD (and slab top temperature) variability. Our models predict that the high temperatures recorded within early stage exhumed rocks (e.g., Platt, 1975; Cloos, 1985; Agard et al., 2018; 2020) coincide with the very low DDs that occur before the cold nose of the mantle wedge has had time to thicken substantially (i.e., during the initiation phase). This early-stage cooling (at a given depth) is in agreement with previous dynamic (Kincaid and Sacks, 1997; Yamato et al., 2007) and kinematically-driven (e.g., Hall, 2012; van Keken et al., 2018) modeling studies.

In the mature stage of our reference model, the DD and slab top $P-T$ conditions exhibit minimal 612 variability (Figs. 3, 6a). This is because the DD is capped at the depth that we cut off our weak 613 crust (i.e., maximum depth of decoupling, MDD $=80 \mathrm{~km}$ ). In models that do not impose such a 614 MDD (Fig. 6b,c), the DD continues to increase during the model run (cf. Kincaid and Sacks, 615 1997). The average depth to slab top beneath active volcanic arcs is on the order of $100 \mathrm{~km}$ (e.g., 
616 England and Katz, 2010), which presents an issue for the later stages of such models where the 617 DD increases to substantially greater than $100 \mathrm{~km}$ (as mantle wedge partial melting requires a 618 hot, sub-arc source region). We therefore focused on our model with a shallow crust cutoff, with

619 an $80 \mathrm{~km}$ cutoff depth comparable to that of previous studies (e.g., Wada and Wang, 2009;

620 Syracuse et al., 2010), but note that our decoupling parameterization only impacts thermal

621 evolution during very mature subduction. In nature, this $\sim 80 \mathrm{~km}$ MDD is likely dictated by a

622 switch from rheologically weak hydrous phases to rheologically strong anhydrous phases in

623 either the crust (i.e., as parameterized in our models) or in the mantle wedge (Hirauchi and

624 Katayama, 2013; Agard et al., 2020; Peacock and Wang, 2020). Given the strong temperature

625 dependence of dehydration reactions (Fig. S6), and continually evolving thermal conditions (e.g.,

626 Fig. 3), this depth can be expected to vary substantially through a subduction zone's lifetime

627 (e.g., Agard et al., 2020).

\subsection{Comparison of modeled and Earth subduction zones}

To check that our reference model is aligned with subduction observables, we compare the $P-T$ conditions of our model with global compilations of those inferred from exhumed rocks and melt inclusions within arc eruptives (Fig. 3). Our slab top temperatures are within the global range of sub-arc slab top temperatures estimated by applying the $\mathrm{H}_{2} \mathrm{O} / \mathrm{Ce}$ thermometer to melt inclusions (Cooper et al., 2012: $733-901{ }^{\circ} \mathrm{C}$ at depths of $80-169 \mathrm{~km}$ ) and, as discussed in more detail in Section 4.4.1, our slab Moho and slab top profiles sweep through much of the $P-T$ space represented by metamorphic rocks exhumed at oceanic subduction zones (Agard et al., 2018).

Due to the generic nature of our models, it is inappropriate to use this model as a direct proxy for any specific Earth subduction zone. However, to again check the first-order behavior, we conduct a cursory comparison with subduction in Northeast Japan (Honshu). Japan is chosen as it contains a similarly old subducting plate (130 Ma relative to $121 \mathrm{Ma}$ ), a young upper plate, and a similar mode of subduction (slab flattened above the lower mantle) as produced in the mature phase of our model. Relative to this mature phase, the main differences are lower modeled convergence rates $(\approx 3 \mathrm{~cm} / \mathrm{yr})$ than observed $(\approx 8 \mathrm{~cm} / \mathrm{yr})$ and a younger modeled subduction duration (32 Myr) than that suggested by Jurassic volcanic deposits (Miyazaki et al., 2016). Regarding the latter, we note that Izanagi-Pacific ridge subduction is likely to have partially reset the thermal structure at $\sim 50 \mathrm{Ma}(\mathrm{Wu}$ and $\mathrm{Wu}, 2019)$ so that the effective thermal age is closer to that of our models. Earlier in the model evolution, towards the end of the free-sinking phase, we have equivalent convergence rates $(\approx 8 \mathrm{~cm} / \mathrm{yr}$ at $t \approx 14 \mathrm{Myr}$ ) but a slab morphology less similar to that of the Japan slab (i.e., without a flat slab).

During the mature phase, modeled surface heat flow is comparable with that of Northeastern Japan. Excluding local variability due to shallow magmatic intrusion, the surface heat flow increases by about $50 \mathrm{~mW} / \mathrm{m}^{2}$ from forearc to arc (Tanaka et al., 2004; Wada and Wang, 2009). Our models exhibit a similar, $\approx 55 \mathrm{~mW} / \mathrm{m}^{2}$ forearc-to-arc increase in surface heat flow. 
657 Considering arc location, the depth to slab top beneath the Japan volcanic arc is $\approx 95 \mathrm{~km}$

658 (England and Katz, 2010). If we assume a simple parameterization of thermally controlled

659 mantle wedge melting, which focuses partial melting at the trench-ward extent of temperatures

660 between $1200{ }^{\circ} \mathrm{C}$ and $1350{ }^{\circ} \mathrm{C}$ (e.g., Tatsumi, 1986; Kelemen et al., 2003), we can estimate an 661 equivalent model depth. For the mature phase, the trench-ward extent of the $1200{ }^{\circ} \mathrm{C}$ isotherm 662 corresponds to a depth to slab top of $88 \mathrm{~km}$ and, for the $1300^{\circ} \mathrm{C}$ isotherm, this depth is $101 \mathrm{~km}$ 663 (Fig. S13). Both are comparable to the $\approx 95 \mathrm{~km}$ observed. During the end of the free-sinking 664 phase, where convergence rate is equivalent to that of Northeastern Japan $(\approx 8 \mathrm{~cm} / \mathrm{yr})$ but slab 665 morphology and subduction duration are less similar, our modeled mantle wedge is hotter than 666 that suggested by arc location and heat flow. This is demonstrated by a shallower sub-arc depth 667 to slab top ( $\approx 80 \mathrm{~km}$ using the $1300^{\circ} \mathrm{C}$ isotherm) and elevated forearc-to-arc surface heat flow 668 increase $\left(\approx 85 \mathrm{~mW} / \mathrm{m}^{2}\right)$. It therefore appears that, during this earlier phase, the close proximity to 669 (hot) subduction initiation is the main factor behind this discrepancy. During the more mature phase, the more comparable slab age and subduction duration produce a better thermal fit despite 671 the lower model convergence rate.

These comparisons illustrate the challenges associated with attaching dynamic and timedependent models to specific subduction zones. Despite this, the first-order agreement gives us confidence in the general applicability of our models to understanding the thermal evolution of Earth subduction zones.

\subsection{Limitations of our approach}

To target first order relations, we neglect a number of processes that impact subduction zone thermal structure. Here, we point out a selection of these processes. Regarding heat transport, mantle flow in the $3^{\text {rd }}$ dimension (e.g., Kincaid and Griffiths, 2003; Plunder et al., 2018) and melt and fluid flow (e.g., Rotman and Spinelli, 2013) have both been shown to exert a control in previous modeling studies. Small-scale convection (e.g., Honda and Saito, 2003; Davies et al., 2016) and buoyant upwellings of meta-sedimentary plumes or diapirs (Gerya and Yuen, 2003; Behn et al., 2011) may also play a role. Furthermore, radiogenic and shear heating and are two important heat sources that can be expected to increase subduction zone temperatures relative to those modeled here. Shear heating has been shown to elevate slab top temperatures particularly within the relatively shallow portion of the forearc that undergoes brittle/frictional deformation (e.g., Molnar and England, 1990; Peacock, 1992; Gao and Wang, 2014).

It is with these simplifications in mind that we have focused on relative temperature variation as

693 a function of time, as opposed to absolute temperatures. We speculate that most of these

694 complexities will increase the time dependence of subduction zone thermal structure, as a result 695 of additional dependencies of time evolving properties like convergence rate. As we progress to 696 applying dynamic models to the thermal structure of specific subduction zones, an assessment of 697 the importance of such complexities within a particular setting will be critical. 


\subsection{Geologic implications}

Temporal changes of subduction zone thermal structure can be expected to be imprinted on a large number of geological phenomena. Here, we briefly discuss two: time-dependent changes in the pressure-temperature conditions of exhumed metamorphic rocks, and in the metamorphic dehydration reactions experienced by the down-going oceanic lithosphere.

\subsubsection{Comparison to the exhumed rock record}

In the case of exhumed metamorphic rocks, recorded temperatures are generally $100-300{ }^{\circ} \mathrm{C}$ warmer (Penniston-Dorland et al., 2015) than the equivalent depth temperatures generated with kinematically driven models of slab zone thermal structure (Gerya et al., 2002; Syracuse et al., 2010). The temperature discrepancy is reduced when continental rocks are omitted from compilations (Agard et al., 2018), but certain models remain colder than the rocks (Syracuse et al., 2010). Inspired by the possibility that metamorphic rocks could be preferentially exhumed during certain, anomalously hot, subduction phases (e.g., Abers et al., 2017; van Keken et al., 2018), we overlay Agard et al.'s (2018) exhumed rock compilation on our modeled slab top $P-T$ evolution that consists of various dynamic subduction phases (Fig. 3a). Initially, modeled shear zone temperatures overlay the cooler-end of $P-T$ space represented by metamorphic soles; the hottest rocks exhumed during the earliest stages of subduction (e.g., Platt, 1975; Cloos, 1985; Agard et al., 2018). Subsequently, and as the initially flat-lying crust replaces the shear zone material, slab top temperatures sweep through a significant proportion of the $P-T$ space covered by colder rocks exhumed during sustained subduction. Because we consider a generic subduction zone, with simplifying assumptions, we cannot assess $P$ - $T$ conditions related to specific regions and/or the contribution of additional heat sources (e.g., shear heating, radiogenic heating, fluid transport). However, this demonstrates that dynamic variability in slab evolution can produce a wide range of $P-T$ conditions over the history of a single subduction zone.

Moreover, the various thermal phases of our dynamic models may have an effect on the likelihood of rock recovery at various times during subduction. Agard et al. $(2009 ; 2018)$ show that the exhumed rock record is dominated by early (initiation) and late stage (mature) exhumation and that intermediate stage rocks are underrepresented. In our models, the intermediate stage is associated with rapid convergence rates and anomalously cold slab Moho temperatures (Fig. 2). While we do not model any of the processes related to rock detachment and exhumation (e.g., Gerya et al., 2002; Yamato et al., 2007; Ruh et al., 2015), both low temperatures and rapid rates could indeed have a negative effect on rock detachment (Ruh et al., 2015; Agard et al., 2018). Taken together, and as recently discussed by Peacock (2020), our dynamic models emphasize the importance of identifying the specific dynamic phase of subduction during which rocks of interest were exhumed. 


\subsubsection{Dehydration of oceanic lithosphere}

Coupling these thermal structures to thermodynamic models of MORB and DMM yields patterns of metamorphic dehydration that are also time-dependent, due to the strong control of temperature on devolitization reactions. The location and magnitude of dehydration from oceanic lithosphere has important implications for a range of geodynamic, geochemical, and tectonic processes (e.g., Peacock, 2001; Hacker et al., 2003; Bebout, 2007). During the initiation phase of subduction, due to the warm slab top, all mineral-bound $\mathrm{H}_{2} \mathrm{O}$ is lost from the downgoing oceanic crust at shallow forearc depths (Fig. 4a), delivering ample serpentinizing fluid to the developing cold mantle wedge corner. Using a similar approach, Abers et al., (2017) surmised that cold mantle wedges would only be hydrated in the warmest subduction zones and presented geophysical data for serpentinized mantle wedge in the warm Cascadia subduction zone. At the slab Moho during this initiation phase, $\mathrm{H}_{2} \mathrm{O}$ is lost from any hydrated lithospheric mantle at subarc depths due to a combination of a colder slab Moho $P-T$ path than slab top, and the stability fields of hydrous phases in DMM (Figs. 3, 4b, S6). This implies that fluids in arc source regions are sourced from the devolatilization of ultramafic mantle during the initial stages of subduction (e.g., Rüpke et al., 2004).

756

In the intermediate and mature phases of subduction, our analysis indicates that MORB dehydration at the slab top releases up to $5 \mathrm{wt} \% \mathrm{H}_{2} \mathrm{O}$ between $60-90 \mathrm{~km}$, providing the likely source fluids for partial melting in the subarc mantle (Fig. 4a). At the same time, because the slab Moho has cooled considerably during the initiation and free sinking phases, hydrous minerals (antigorite) within our thermodynamic model space do not warm up enough to break down during the mature phase of subduction. Therefore, any hydrated mantle at the slab Moho and within the core of the mantle lithosphere of the slab will be carried past $\sim 4.5 \mathrm{GPa}(>150 \mathrm{~km})$ (e.g., Figs. 4b, S6) and delivered to the deeper mantle after $\sim 8 \mathrm{Myr}$.

Other workers have suggested this same trend of dehydration of MORB along the slab top at subarc depths within intermediate to cold subduction zones, while oceanic mantle lithosphere likely carries fluids beyond the arc into the mantle (e.g., Hacker et al., 2008; van Keken et al., 2011; Grove et al., 2012; Rüpke et al., 2004). Our results complement this previous work, which focused on kinematic-dynamic models, by providing a dynamic framework for the variability that these dehydration patterns may exhibit during subduction zone evolution. Of course, our analysis is limited by the assumption of fluid saturation, which while likely appropriate for the slab top based on geologic observations (e.g., Bebout and Penniston-Dorland, 2016), is not likely for the mantle lithosphere or the gabbroic core the subducting oceanic crust (e.g., Faccenda, 2014). The degree and distribution of hydration within the subducting slab mantle is likely controlled by the degree and depth of fluid infiltration along fractures formed as the slab bends before the trench (e.g., Naif et al., 2015; Korenaga, 2017), or the subduction of hydrated oceanic transform zones (e.g., Prigent et al., 2020). This analysis also assumes chemical equilibrium, the limitations of which are discussed in Condit et al. (2020). Variation in sea floor alteration and 
metasomatism can influence the composition of subducting oceanic crust and manifest in subtle variations in dehydration locations and magnitudes (e.g., Hernandez-Uribe et al., 2020). However, even given these caveats, our analysis demonstrates that the time evolving thermal structure of dynamic subduction zones can be expected to manifest in strong temporal variation in crust and mantle dehydration during the lifetime of a subduction zone, and that this temporal variation in dehydration is broadly in agreement with geological observations.

\section{CONCLUSION}

We have used time evolving and dynamically consistent numerical models to explore how subduction zone thermal structure evolves over the lifetime of a subduction zone. We find that pressure-temperature $(P-T)$ conditions along the slab Moho and slab top exhibit substantial variability through during the phases of subduction: initiation, free sinking, and mature subduction. This variability occurs in response to temporal changes in subduction properties (e.g., fast convergence during free sinking vs. slow convergence during mature subduction), and the inheritance of thermal structure from previous subduction phases (e.g., due to forearc thickening).

During subduction initiation, slab Moho and slab top temperatures both decrease rapidly at a given depth. After which, slab Moho temperatures exhibit an additional cooling phase associated with rapid convergence during the slab's free sinking phase. Once the slab impinges on the strong lower mantle, the convergence rate reduces, and significant cooling terminates. Slab top temperatures are less dependent on convergence rate but strongly dependent on the vertical extent of the cold and stiff mantle wedge corner. In our models, the vertical extent of this region increases as the upper plate progressively ages and thickens. This imparts a cooling trend on the slab top that, in the case of our reference model with a crust that is cutoff at $80 \mathrm{~km}$ depth, persists until the geometry of this wedge corner region reaches near steady state during mature subduction.

This dynamic temperature evolution manifests in a range of geological observables. In addition to confirming first order model agreement with surface heat flow measurements, arc locations, and slab $P-T$ estimates from melt inclusion geochemistry, the $P-T$ conditions experienced by the slab top of our reference model sweep through a significant proportion of the $P-T$ space recorded by exhumed rocks during $\sim 50$ Myrs of modeled subduction evolution. In addition to substantiating previous suggestions that variability in the exhumed rock record could relate to various dynamic phases of subduction evolution, evolving $P$ - $T$ conditions imply large variability in the location and magnitude of oceanic lithosphere dehydration over the lifetime of a

817 subduction zone. In the early stages of subduction, hydrated mantle lithosphere at the slab Moho 818 provides the bulk of hydrous fluids at subarc depths, while MORB at the slab top dehydrates at 819 shallow forearc depths. During the free sinking and mature phases, MORB releases water at near

820 to subarc depths, while hydrated ultramafic rocks along the slab Moho carry fluids into the 
821 deeper mantle well beyond the subarc region. This simple analysis indicates that time-dependent

822 thermal structure has profound impacts on the global water cycle and fluids in arc source regions.

824 This work emphasizes the need to consider subduction zone thermal structure as dynamically 825 evolving. Parameterization of this dynamic evolution is required to extrapolate inferences about 826 modern subduction behavior, like slab dehydration, into the geological past. To accurately 827 interpret observables originating from earlier in a subduction zone's lifetime, consideration of 828 the dynamic subduction phase corresponding to the origin of that particular observable is needed.

\section{ACKNOWLEDGEMENTS}

This work has benefited from scientific discussions with Ben Klein, Victor Guevara, Mélanie Gérault, Thorsten Becker, Whitney Behr, and Leigh Royden. We also thank Simon Peacock and an anonymous reviewer for constructive comments that significantly improved the manuscript. The computations of this work used the Extreme Science and Engineering Discovery Environment (XSEDE), which is supported by National Science Foundation (NSF) grant number ACI-15485x62. We also thank the Computational Infrastructure for Geodynamics (geodynamics.org), which is funded by the NSF under awards EAR-0949446 and EAR-1550901, for supporting the development of ASPECT. The ASPECT files needed to run the models are available in the following permanent Zenodo repository (https://doi.org/10.5281/zenodo.4543413).

\section{REFEERENCES}

Abers, G.A., Van Keken, P.E., Hacker, B.R., 2017. The cold and relatively dry nature of mantle forearcs in subduction zones. Nature Geoscience, 10, 333-337. https://doi.org/10.1038/ngeo292

Agard, P., Plunder, A., Angiboust, S., Bonnet, G., Ruh, J., 2018. The subduction plate interface: rock record and mechanical coupling (from long to short timescales). Lithos, 320-321, 537566. https://doi.org/10.1016/j.lithos.2018.09.029

Agard, P., Prigent, C., Soret, M., Dubacq, B., Guillot, S., Deldicque, D., 2020. Slabitization: Mechanisms controlling subduction development and viscous coupling. Earth-Science Reviews, 208, https://doi.org/10.1016/j.earscirev.2020.103259

Agard, P., Yamato, P., Jolivet, L., Burov, E., 2009. Exhumation of oceanic blueschists and eclogites in subduction zones: Timing and mechanisms. Earth-Science Reviews, 92, 53-79. https://doi.org/10.1016/j.earscirev.2008.11.002

Agard, P., Yamato, P., Soret, M., Prigent, C., Guillot, S., Plunder, A., Dubacq, B., Chauvet, A., Monié, P., 2016. Plate interface rheological switches during subduction infancy: Control on slab penetration and metamorphic sole formation. Earth and Planetary Science Letters, 451, 208-220, https://doi.org/10.1016/j.epsl.2016.06.054 
Arcay, D., 2012. Dynamics of interplate domain in subduction zones: Influence of rheological parameters and subducting plate age. Solid Earth, 3(2), 467-488. https://doi.org/10.5194/se3-467-2012

Arcay, D., Tric, E., Doin, M.P., 2007. Slab surface temperature in subduction zones: Influence of the interplate decoupling depth and upper plate thinning processes. Earth and Planetary Science Letters, 255(3-4), 324-338. https://doi.org/10.1016/j.epsl.2006.12.027

Arcay, D., 2017. Modelling the interplate domain in thermo-mechanical simulations of subduction: Critical effects of resolution and rheology, and consequences on wet mantle melting. Physics of the Earth and Planetary Interiors, 269, 112-132. https://doi.org/10.1016/j.pepi.2017.05.008

Bangerth W., Dannberg, J., Gassmoeller, R., Heister., T., 2020a. ASPECT v2.1.0. (version v2.1.0). Zenodo. https://doi.org/10.5281/ZENODO.3924604.

Bangerth, W., Dannberg, J., Gassmoeller, R., Heister, T., and others. 2020b. ASPECT: Advanced Solver for Problems in Earth's ConvecTion, User Manual. https://doi.org/10.6084/m9.figshare.4865333

Beall, A., Fagereng, Å., Davies, J.H., Garel, F., Davies, D.R., 2020. Influence of Subduction Zone Dynamics on Interface Shear Stress and Potential Relationship with Seismogenic Behavior. Geochemistry, Geophysics, Geosystems, https://doi.org/10.1029/2020GC009267

Bebout, G.E., Penniston-Dorland, S.C., 2016. Fluid and mass transfer at subduction interfacesThe field metamorphic record. Lithos, 240-243, 228-258, https://doi.org/10.1016/j.lithos.2015.10.007

Becker, T.W., 2006. On the effect of temperature and strain-rate dependent viscosity on global mantle flow, net rotation, and plate-driving forces. Geophysical Journal International, 167(2), 943-957, https://doi.org/10.1111/j.1365-246X.2006.03172.x

Behn, M.D., Kelemen, P.B., Hirth, G., Hacker, B.R., Massonne, H.J., 2011. Diapirs as the source of the sediment signature in arc lavas. Nature Geoscience, 4, 641-646, https://doi.org/10.1038/ngeo1214

Behr, W.M., Becker, T.W., 2018. Sediment control on subduction plate speeds. Earth and Planetary Science Letters, 502, 166-173, https://doi.org/10.1016/j.epsl.2018.08.057

Byerlee, J., 1978. Friction of rocks. Pure and Applied Geophysics, 116 (4-5), 615-626 https://doi.org/10.1007/BF00876528

Cerpa, N.G., Hassani, R., Gerbault, M., Prévost, J.H., 2014. A fictitious domain method for lithosphere-asthenosphere interaction: Application to periodic slab folding in the upper mantle. Geochemistry, Geophysics, Geosystems, 15(5), 1852-1877, https://doi.org/10.1002/2014GC005241 
Clark, S.R., Stegman, D., Müller, R.D., 2008. Episodicity in back-arc tectonic regimes. Physics of the Earth and Planetary Interiors, 171(1-4), 265-279, https://doi.org/10.1016/j.pepi.2008.04.012

Cloos, M., 1985. Thermal evolution of convergent plate margins: Thermal modeling and reevaluation of isotopic AR-ages for Blueschists in the Franciscan Complex of California. Tectonics, 4, 421-433, https://doi.org/10.1029/TC004i005p00421

Condit, C. B., V. E. Guevara, J. R. Delph, French, M. E., 2020. Slab dehydration in warm subduction zones at depths of epsiodic slip and tremor, Earth and Planetary Science Letters, 552, https://doi.org/10.1016/j.epsl.2020.116601

Connolly, J.A.D., Petrini, K., 2002. An automated strategy for calculation of phase diagram sections and retrieval of rock properties as a function of physical conditions. Journal of Metamorphic Geology, 20, 697-708, https://doi.org/10.1046/j.1525-1314.2002.00398.x

Cottrell, E., Kelley, K.A., 2011. The oxidation state of Fe in MORB glasses and the oxygen fugacity of the upper mantle, Earth and Planetary Science Letters, 305(3-4), 270-282, doi:10.1016/j.eps1.2011.03.014.

Cooper, L.B., Ruscitto, D.M., Plank, T., Wallace, P.J., Syracuse, E.M., Manning, C.E., 2012. Global variations in $\mathrm{H}_{2} \mathrm{O} / \mathrm{Ce}$ : 1 . Slab surface temperatures beneath volcanic arcs. Geochemistry, Geophysics, Geosystems, 13, 1-27 https://doi.org/10.1029/2011GC003902

Currie, C.A., Wang, K., Hyndman, R.D., He, J., 2004. The thermal effects of steady-state slabdriven mantle flow above a subducting plate: The Cascadia subduction zone and backarc. Earth and Planetary Science Letters, 223(1-2), 35-48, https://doi.org/10.1016/j.eps1.2004.04.020

Davies, D.R., Le Voci, G., Goes, S., Kramer, S.C., Wilson, C.R., 2016. The mantle wedge's transient 3-D flow regime and thermal structure. Geochemistry, Geophysics, Geosystems, 17(1), 78-100, https://doi.org/10.1002/2015GC006125

Davies, J.H., 1999. Simple analytic model for subduction zone thermal structure. Geophysical Journal International, 139(3), 823-828, https://doi.org/10.1046/j.1365-246x.1999.00991.x

Dymkova, D., Gerya, T., 2013. Porous fluid flow enables oceanic subduction initiation on Earth. Geophysical Research Letters, 40(21), 5671-5676, https://doi.org/10.1002/2013GL057798

Eberle, M.A., Grasset, O., Sotin, C., 2002. A numerical study of the interaction between the mantle wedge, subducting slab, and overriding plate. Physics of the Earth and Planetary Interiors, 134(3-4), 191-202, https://doi.org/10.1016/S0031-9201(02)00157-7

England, P.C., Katz, R.F., 2010. Melting above the anhydrous solidus controls the location of volcanic arcs. Nature, 467, 700-703, https://doi.org/10.1038/nature09417 
Enns, A., Becker, T.W., Schmeling, H., 2005. The dynamics of subduction and trench migration for viscosity stratification. Geophysical Journal International, 160, 761-775, https://doi.org/10.1111/j.1365-246X.2005.02519.x

Faccenda, M. (2014), Water in the slab: A trilogy, Tectonophysics, 614, 1-30, doi:10.1016/j.tecto.2013.12.020.

Faccenna, C., Becker, T.W., Lucente, F.P., Jolivet, L., Rossetti, F., 2001. History of subduction and back-arc extension in the central Mediterranean. Geophysical Journal International, 145(3), 809-820, https://doi.org/10.1046/j.0956-540X.2001.01435.x

Funiciello, F., Faccenna, C., Heuret, A., Lallemand, S., Di Giuseppe, E., Becker, T.W., 2008. Trench migration, net rotation and slab-mantle coupling. Earth and Planetary Science Letters, 271(1-4), 233-240, https://doi.org/10.1016/j.eps1.2008.04.006

Funiciello, F., Faccenna, C., Giardini, D., 2004. Role of lateral mantle flow in the evolution of subduction systems: Insights from laboratory experiments. Geophysical Journal International, 157(3), 1393-1406, https://doi.org/10.1111/j.1365-246X.2004.02313.x

Furukawa, Y., 1993. Depth of the decoupling plate interface and thermal structure under arcs. Journal of Geophysical Research, 98, 20,005-20,013, https://doi.org/10.1029/93jb02020

Gale, A., C. A. Dalton, C. H. Langmuir, Y. Su, Schilling, J.G., 2013. The mean composition of ocean ridge basalts, Geochemistry, Geophysics, Geosystems, 14(3), 489-518, doi:10.1029/2012GC004334.

Gao, X., Wang, K., 2014. Strength of stick-slip and creeping subduction megathrusts from heat flow observations. Science, 345(6200), 1038-1041, https://doi.org/10.1126/science.1255487

Garel, F., Goes, S., Davies, D.R., Davies, J.H., Kramer, S.C., Wilson, C.R., 2014. Interaction of subducted slabs with the mantle transition-zone: A regime diagram from 2-D thermomechanical models with a mobile trench and an overriding plate. Geochemistry, Geophysics, Geosystems, 15(5), 1739-1765.

Gerya, T. V., Stöckhert, B., Perchuk, A.L., 2002. Exhumation of high-pressure metamorphic rocks in a subduction channel: A numerical simulation. Tectonics, 21(6), https://doi.org/10.1029/2002tc001406

Gerya, T. V., Yuen, D.A., 2003. Rayleigh-Taylor instabilities from hydration and melting propel "cold plumes" at subduction zones. Earth and Planetary Science Letters, 212, 47-62. https://doi.org/10.1016/S0012-821X(03)00265-6

Grevemeyer, I., Ranero, C.R., and Ivandic, M., 2018, Structure of oceanic crust and serpentinization at subduction trenches: Geosphere, 14, (2), 395-418, https://doi.org/10.1130/GES01537.1 
Groppo, C., Beltrando, M., Compagnoni, R., 2009. The P-T path of the ultra-high pressure Lago Di Cignana and adjoining high-pressure meta-ophiolitic units: insights into the evolution of the subducting Tethyan slab. Journal of Metamorphic Geology, 27(3), 207-231. https://doi.org/10.1111/j.1525-1314.2009.00814.x

Grove, T.L., Till, C.B., Lev, E., Chatterjee, N., Médard, E., 2009. Kinematic variables and water transport control the formation and location of arc volcanoes. Nature, 459, 694-697, https://doi.org/10.1038/nature08044

Grove, T.L., Till, C.B., Krawczynski, M.J., 2012. The role of $\mathrm{H}_{2} \mathrm{O}$ in subduction zone magmatism. Annual Reviews of Earth and Planetary Sciences, 40, 413-439, https://doi.org/10.1146/annurev-earth-042711-105310

Guillot, S., Hattori, K., Agard, P., Schwartz, S., Vidal, O., 2009. Exhumation processes in oceanic and continental subduction contexts: A review. In S. Lallemand, \& F. Funiciello (Eds.), Subduction zone geodynamics, Frontiers in Earth Sciences (pp. 175-205). Berlin, Germany: Springer.

Hacker, B.R., 2008. $\mathrm{H}_{2} \mathrm{O}$ subduction beyond arcs. Geochemistry, Geophysics, Geosystems, 9, Q03001, https://doi.org/10.1029/2007GC001707

Hacker, B. R., Peacock, S. M., Abers, G. A., and Holloway, S. D. (2003), Subduction factory 2. Are intermediate-depth earthquakes in subducting slabs linked to metamorphic dehydration reactions? Journal of Geophysical. Research., 108, 2030, https://doi.org/10.1029/2001JB001129,

Hager, B.H., 1984. Subducted slabs and the geoid: constraints on mantle rheology and flow. Journal of Geophysical Research, 89, 6003-6015, https://doi.org/10.1029/JB089iB07p06003

Hall, P.S., 2012. On the thermal evolution of the mantle wedge at subduction zones. Physics of the Earth and Planetary Interiors, 198-199, 9-27. https://doi.org/10.1016/j.pepi.2012.03.004

Heister, T., Dannberg, J., Gassmöller, R., Bangerth, W., 2017. High accuracy mantle convection simulation through modern numerical methods - II: Realistic models and problems. Geophysical Journal International, 210(2), 833-851, https://doi.org/10.1093/gji/ggx195

Hernández-Uribe, D., Palin, R.M., 2019. A revised petrological model for subducted oceanic crust: Insights from phase equilibrium modelling. Journal of Metamorphic Geology, 37 , 745-768. https://doi.org/10.1111/jmg.12483

Hernández-Uribe, D., Palin, R.M., Cone, K.A., Cao, W., 2020. Petrological implications of seafloor hydrothermal alteration of subducted mid-ocean ridge basalt. Journal of Petrology, 61(9), doi:10.1093/petrology/egaa086

Hirauchi, K., Katayama, I., 2013. Rheological contrast between serpentine species and 
implications for slab-mantle wedge decoupling. Tectonophysics, 608, 545-551. https://doi.org/10.1016/j.tecto.2013.08.027

Hirth, G., Kohlstedt, D.L., 2003. Rheology of the Upper Mantle and the Mantle Wedge: a View From the Experimentalists. In Inside the Subduction Factory, Geophysical Monograph Series 138, 83-106, American Geophysical Union, Washington, D.C.

Holland, T., Powell, R., 1991. A Compensated-Redlich-Kwong (CORK) equation for volumes and fugacities of $\mathrm{CO}_{2}$ and $\mathrm{H}_{2} \mathrm{O}$ in the range 1 bar to $50 \mathrm{kbar}$ and $100-1600^{\circ} \mathrm{C}$, Contributions to Mineralogy and Petrology, 109(2), 265-273, doi:10.1007/BF00306484.

Holland, T., Powell, R., 1998. An internally consistent thermodynamic data set for phases of petrological interest, Journal of Metamorphic Geology, 16, 309-343, doi:10.1111/J.15251314.1998.00140.X

Holland, T., Powell, R., 2011. An improved and extended internally consistent thermodynamic dataset for phases of petrological interest, involving a new equation of state for solids, Journal of Metamorphic Geology, 29(3), 333-383, doi:10.1111/j.1525-1314.2010.00923.x.

Holt, A.F., Becker, T.W., Buffett, B.A., 2015. Trench migration and overriding plate stress in dynamic subduction models. Geophysical Journal International, 201, 172-192. https://doi.org/10.1093/gji/ggv011

Holt, A.F., Becker, T.W., 2017. The effect of a power-law mantle viscosity on trench retreat rate. Geophysical Journal International, 208, 491-507, https://doi.org/10.1093/gii/ggw392

Holt, A. F., Royden, L. H., Becker, T. W., 2017. The dynamics of double slab subduction. Geophysical Journal International, 209, 250-265, doi:10.1093/gji/ggw496.

Honda, S., 1985. Thermal structure beneath Tohoku, northeast Japan. Tectonophysics. 112(1-4), 69-102, https://doi.org/10.1016/0040-1951(85)90173-8

Honda, S., Saito, M., 2003. Small-scale convection under the back-arc occurring in the low viscosity wedge. Earth and Planetary Science Letters, 216(4), 703-715, https://doi.org/10.1016/S0012-821X(03)00537-5

Iaffaldano, G., Bunge, H.P., 2015. Rapid plate motion variations through geological time: Observations serving geodynamic interpretation. Annual Reviews of Earth and Planetary Sciences, 43, 571-592, https://doi.org/10.1146/annurev-earth-060614-105117

Jarrard, R. D. (2003), Subduction fluxes of water, carbon dioxide, chlorine, and potassium, Geochemistry, Geophyics, Geosystems., 4, 8905, doi:10.1029/2002GC000392

Karato, S.I., Wu, P., 1993. Rheology of the upper mantle: A synthesis. Science, 260, 771-778, https://doi.org/10.1126/science.260.5109.771 
Kelemen, P.B., Rilling, J.L., Parmentier, E.M., Mehl, L., Hacker, B.R., 2004. Thermal structure due to solid-state flow in the mantle wedge beneath arcs. In Inside the Subduction Factory, Geophysical Monograph Series 138, 293-311, American Geophysical Union, Washington, D.C.

Kincaid, C., Griffiths, R.W., 2003. Laboratory models of the thermal evolution of the mantle during rollback subduction. Nature, 425, 58-62, https://doi.org/10.1038/nature01923

Kincaid, C., Sacks, I.S., 1997. Thermal and dynamical evolution of the upper mantle in subduction zones. Journal of Geophysical Research Solid Earth, 102, 12295-12315. https://doi.org/10.1029/96jb03553

King, S.D., Ita, J.J., 2005. Subduction and volatile recycling in earth's mantle. AIP Conference Proceedings, 341, 33-44. https://doi.org/10.1063/1.48748

Kirby, S., Engdahl, E.R., Denlinger, R., 1996. Intermediate-depth intraslab earthquakes and arc volcanism as physical expressions of crustal and uppermost mantle metamorphism in subducting slabs. In Subduction Topo to Bottom, Geophysical Monograph Series 96, $195-$ 214, American Geophysical Union, Washington, D.C.

Korenaga, J., 2017. On the extent of mantle hydration caused by plate bending. Earth and Planetary Science Letters, 457, 1-9, doi:10.1016/j.eps1.2016.10.011

Krebs, M., Schertl, H.-P., Maresch, W.V., Draper, G. Mass flow in serpentinite-hosted subduction channels: P-T-t path patterns of metamorphic blocks in the Rio San Juan mélange (Dominican Republic). Journal of Asian Earth Sciences, 42(4), 569-595, https://doi.org/10.1016/j.jseaes.2011.01.011.

Kronbichler, M., Heister, T., Bangerth, W., 2012. High accuracy mantle convection simulation through modern numerical methods. Geophysical Journal International, 191(1), 12-29, https://doi.org/10.1111/j.1365-246X.2012.05609.x

Lázaro, C., García-Casco, A., Agramonte Y.R., Kröner A., Neubauer F., Iturralde-Vinent, M.A., 2009. Fifty-five-million-year history of oceanic subduction and exhumation at the northern edge of the Caribbean plate (Sierra del Convento melange, Cuba), Journal of Metamorphic Geology, 27,19-40

Matsumoto, T., Tomoda, Y., 1983. Numerical simulation of the initiation of subduction at the fracture zone. Journal of Physics of the Earth, 31, 183-194. https://doi.org/10.4294/jpe1952.31.183

Maunder, B., Goes, S., van Hunen, J., Prytulak, J., P., Magni, V., Bouilhol, P., 2018. The Decoupling Depth and Slab Thermal Structure. Abstract DI23B-0030 presented at 2018 Fall Meeting, American Geophysical Union, Washington, D.C., 10-14 Dec. 
Maunder, B., van Hunen, J., Bouilhol, P., Magni, V., 2019. Modeling Slab Temperature: A Reevaluation of the Thermal Parameter. Geochemistry, Geophys. Geosystems. 20, 673-687. https://doi.org/10.1029/2018GC007641

McKenzie, D.P., 1969. Speculations on the Consequences and Causes of Plate Motions. Geophysical Journal of the Royal Astronomical Society, 18, 1, https://doi.org/10.1111/j.1365-246X.1969.tb00259.x

Miyashiro, A., F. Shido, Ewing, E., 1969. Composition and origin of serpentinites from the MidAtlantic Ridge near $24^{\circ}$ and $30^{\circ}$ North Latitude, Contributions to Mineralogy and Petrology, 23(2), 117-127, doi:10.1007/BF00375173.

Miyazaki, K., Ozaki, M., Saito, M., Toshimitsu, S., 2016. The Kyushu-Ryukyu Arc, in: The Geology of Japan. https://doi.org/10.1144/goj.

Molnar, P., England, P., 1990. Temperatures, heat flux, and frictional stress near major thrust faults. Journal of Geophysical Research, 95(B4), 4833-4856.

https://doi.org/10.1029/JB095iB04p04833

Molnar, P., England, P., 1995. Temperatures in zones of steady-state underthrusting of young oceanic lithosphere. Earth and Planetary Science Letters,131(1-2), 57-70. https://doi.org/10.1016/0012-821X(94)00253-U

Sdrolias, M., Müller, R.D., 2006. Controls on back-arc basin formation. Geochemistry, Geophysics, Geosystems, 7(4), https://doi.org/10.1029/2005GC001090.

Naif, S., K. Key, S. Constable, Evans, R. L., 2015. Water-rich bending faults and the Middle America Trench. Geochemistry Geophysics, Geosystems, 16(1), 267-300, doi:10.1002/2014GC005684.Key.

Peacock, S.M., 1991. Numerical simulation of subduction zone pressure-temperature-time paths: constraints on fluid production and arc magmatism. Philosophical Transactions of the Royal Society A, 335(1638), 341-353. https://doi.org/10.1098/rsta.1991.0050

Peacock, S.M., 1992. Blueschist-facies metamorphism, shear heating, and P-T-t paths in subduction shear zones. Journal of Geophysical Research: Solid Earth, 97(B12), 1796317707, https://doi.org/10.1029/92JB01768

Peacock, S. M., 2001. Are the lower planes of double seismic zones caused by serpentine dehydration in subducting oceanic mantle? Geology, 29(4), 299-302, doi:10.1130/00917613

Peacock, S.M., 2020. Advances in the thermal and petrologic modeling of subduction zones. Geosphere, 16(4), 936-952. https://doi.org/10.1130/GES02213.1 
Peacock, S.M., Wang, K., 1999. Seismic consequences of warm versus cool subduction metamorphism: Examples from southwest and northeast Japan. Science, 286(5441), 937939. https://doi.org/10.1126/science.286.5441.937

Peacock, S.M., Wang, K., 2020. Does the stability of talc in the mantle wedge control the maximum depth of slab-wedge decoupling in subduction zones? Abstract T052-02 presented at 2020 Fall Meeting, American Geophysical Union, Virtual, 1-17 Dec.

Penniston-Dorland, S.C., Kohn, M.J., Manning, C.E., 2015. The global range of subduction zone thermal structures from exhumed blueschists and eclogites: Rocks are hotter than models. Earth and Planetary Science Letters, 428, 243-254. https://doi.org/10.1016/j.eps1.2015.07.031

Perrin, A., Goes, S., Prytulak, J., Rondenay, S., Davies, D.R., 2018. Mantle wedge temperatures and their potential relation to volcanic arc location. Earth and Planetary Science Letters, 501, 67-77. https://doi.org/10.1016/j.eps1.2018.08.011

Platt, J.P., 1975. Metamorphic and deformational processes in the Franciscan Complex, California: Some insights from the Catalina Schist terrane. GSA Bulletin, 86(10), $1337-$ 1347, https://doi.org/10.1130/0016-7606(1975)86<1337:MADPIT>2.0.CO;2

Plunder, A., Thieulot, C., van Hinsbergen, D.J.J., 2018. The effect of obliquity on temperature in subduction zones: insights from 3-D numerical modeling. Solid Earth, 9, 759-776. https://doi.org/10.5194/se-9-759-2018

Podolefsky, N.S., Zhong, S., McNamara, A.K., 2004. The anisotropic and rheological structure of the oceanic upper mantle from a simpe model of plate shear. Geophysical Journal International, 158(1), 287-296, https://doi.org/10.1111/j.1365-246X.2004.02250.x

Prigent, C., Warren, J.M., Kohli, A.H., Teyssier, C., 2020. Fracture-mediated deep seawater flow and mantle hydration on oceanic transform faults. Earth and Planetary Science Letters, 535, https://doi.org/10.1016/j.eps1.2019.115988

Rotman, H.M.M., Spinelli, G.A., 2013. Global analysis of the effect of fluid flow on subduction zone temperatures. Geochemistry, Geophysics, Geosystems, 14(8), 3268-3281, https://doi.org/10.1002/ggge.20205

Royden, L.H., 1993. The steady state thermal structure of eroding orogenic belts and accretionary prisms. Journal of Geophysical Research, 98(B3), 4487-4507, https://doi.org/10.1029/92JB01954

Ruh, J.B., Pourhiet, L.L., Agard, P., Burov, E.B., Gerya, T., 2015. Tectonic slicing of subducting oceanic crust along plate interfaces: Numerical modeling. Geochemistry, Geophysics, Geosystems, 16, 3505-3531, doi:10.1002/2015GC005998. 
Rüpke, L.H., Morgan, J.P., Hort, M., Connolly, J.A.D., 2004. Serpentine and the subduction zone water cycle. Earth and Planetary Science Letters, 223(1-2), 17-34, https://doi.org/10.1016/j.eps1.2004.04.018

Sandiford, D., Moresi, L., 2019. Improving subduction interface implementation in dynamic numerical models. Solid Earth, 10, 969-985, https://doi.org/10.5194/se-10-969-2019

Schmidt, M. W., Poli, S., 1998. Experimentally based water budgets for dehydrating slabs and consequences for arc magma generation. Earth and Planetary Science Letters, 163, 361379, https://doi.org/10.1016/S0012-821X(98)00142-3

Sdrolias, M., Müller, R.D., 2006. Controls on back-arc basin formation. Geochemistry, Geophysics, Geosystems, 7(4), Q04016, https://doi.org/10.1029/2005GC001090

Stein, C.A., Stein, S., 1992. A model for the global variation in oceanic depth and heat flow with lithospheric age. Nature, 359, 123-129, https://doi.org/10.1038/359123a0

Suenaga, N., Yoshioka, S., Matsumoto, T., Manea, V. C., Manea, M., \& Ji, Y. (2019). Twodimensional thermal modeling of the Philippine Sea plate subduction in central Japan: Implications for gap of low-frequency earthquakes and tectonic tremors. Journal of Geophysical Research: Solid Earth, 124, 6848-6865. https://doi.org/ 10.1029/2018JB017068

Syracuse, E.M., van Keken, P.E., Abers, G.A., 2010. The global range of subduction zone thermal models. Physics of the Earth and Planetary Interiors, 183, 73-90. https://doi.org/10.1016/j.pepi.2010.02.004

Tanaka, A., Yamano, M., Yano, Y., Sasada, M., 2004. Geothermal gradient and heat flow data in and around Japan (I): Appraisal of heat flow from geothermal gradient data. Earth, Planets and Space, 56, 1191-1194, https://doi.org/10.1186/BF03353339

Tatsumi, Y., 1986. Formation of the volcanic front in subduction zones. Geophysical Research Letters, 13, 717-720, https://doi.org/10.1029/GL013i008p00717

van Keken, P.E., Hacker, B.R., Syracuse, E.M., Abers, G.A., 2011. Subduction factory: 4. Depth-dependent flux of $\mathrm{H}_{2} \mathrm{O}$ from subducting slabs worldwide. Journal of Geophysical Research Solid Earth, 116, B01401, https://doi.org/10.1029/2010JB007922

van Keken, P.E., Kiefer, B., Peacock, S.M., 2002. High-resolution models of subduction zones: Implications for mineral dehydration reactions and the transport of water into the deep mantle. Geochemistry, Geophysics, Geosystems, 3(10), 1056, https://doi.org/10.1029/2001GC000256

van Keken, P.E., Wada, I., Abers, G.A., Hacker, B.R., Wang, K., 2018. Mafic High-Pressure Rocks Are Preferentially Exhumed From Warm Subduction Settings. Geochemistry, Geophysics, Geosystems, 19, 2934-2961. https://doi.org/10.1029/2018GC007624 
Wada, I., Wang, K., 2009. Common depth of slab-mantle decoupling: Reconciling diversity and uniformity of subduction zones. Geochemistry, Geophysics, Geosystems, 10(10), 2009Q10009, https://doi.org/10.1029/2009GC002570

Wada, I., Wang, K., He, J., Hyndman, R.D., 2008. Weakening of the subduction interface and its effects on surface heat flow, slab dehydration, and mantle wedge serpentinization. Journal of Geophysical Research Solid Earth, 113(B4), B04402, https://doi.org/10.1029/2007JB005190

Wada, I., Rychert, C.A., Wang, K., 2011. Sharp thermal transition in the forearc mantle as a consequence of nonlinear mantle wedge flow. Geophysical Research Letters, 38(13), https://doi.org/10.1029/2011GL047705

Wu, B., Conrad, C.P., Heuret, A., Lithgow-Bertelloni, C., Lallemand, S., 2008. Reconciling strong slab pull and weak plate bending: The plate motion constraint on the strength of mantle slabs. Earth and Planetary Science Letters, 272(1-2), 412-421, https://doi.org/10.1016/j.eps1.2008.05.009

Wu, J.T.J., Wu, J., 2019. Izanagi-Pacific ridge subduction revealed by a 56 to 46 Ma magmatic gap along the northeast Asian margin. Geology, 47(10), 953-957, https://doi.org/10.1130/G46778.1

Yamato, P., Agard, P., Burov, E., Le Pourhiet, L., Jolivet, L., Tiberi, C., 2007. Burial and exhumation in a subduction wedge: Mutual constraints from thermomechanical modeling and natural P-T-t data (Schistes Lustrés, western Alps). Journal of Geophysical Research Solid Earth, 112, B07410, https://doi.org/10.1029/2006JB004441 
manuscript published in Geochemistry, Geophysics, Geosystems

\begin{tabular}{|c|c|c|c|}
\hline Quantity & Symbol & Units & Value \\
\hline Thermal expansion coefficient & $\alpha$ & $\mathrm{K}^{-1}$ & $3 \times 10^{-5}$ \\
\hline Thermal diffusivity & $\kappa$ & $\mathrm{m}^{2} \mathrm{~s}^{-1}$ & $10^{-6}$ \\
\hline Reference density & $\rho 0$ & $\mathrm{~kg} \mathrm{~m}^{-3}$ & 3300 \\
\hline Surface temperature & $T_{s}$ & $\mathrm{~K}$ & 273 \\
\hline Potential temperature & $T_{m}$ & $\mathrm{~K}$ & 1694.5 \\
\hline Adiabatic temperature gradient & $d_{z} T$ & $\mathrm{~K} \mathrm{~km}^{-1}$ & 0.3 \\
\hline Gravitational acceleration & $g$ & $\mathrm{~m} \mathrm{~s}^{-2}$ & 9.81 \\
\hline Maximum viscosity & $\eta_{\max }$ & $\mathrm{Pas}$ & $2.5 \times 10^{23}$ \\
\hline Minimum viscosity & $\eta_{\min }$ & $\mathrm{Pas}$ & $2.5 \times 10^{18}$ \\
\hline Crust viscosity & $\eta_{C}$ & $\mathrm{Pas}$ & $2.0 \times 10^{20}$ \\
\hline Core viscosity & $\eta_{\text {core }}$ & $\mathrm{Pas}$ & $2.5 \times 10^{23}$ \\
\hline \multicolumn{4}{|c|}{ Dislocation creep (upper mantle) } \\
\hline Activation energy & E & $\mathrm{kJ} \mathrm{mol}^{-1}$ & 540 \\
\hline Activation volume & V & $\mathrm{cm}^{3} \mathrm{~mol}^{-1}$ & 12 \\
\hline Prefactor & $A$ & $\mathrm{~Pa}^{-n} \mathrm{~s}^{-1}$ & $3.275 \times 10^{-16}$ \\
\hline Exponent & $n$ & - & 3.5 \\
\hline \multicolumn{4}{|c|}{ Diffusion creep (upper and lower mantle) } \\
\hline Activation energy & E & $\mathrm{kJ} \mathrm{mol}^{-1}$ & 300 (UM \& LM) \\
\hline Activation volume & V & $\mathrm{cm}^{3} \mathrm{~mol}^{-1}$ & $4(\mathrm{UM}), 2.5(\mathrm{LM})$ \\
\hline \multirow[t]{2}{*}{ Prefactor } & $A$ & $\mathrm{~Pa}^{-1} \mathrm{~s}^{-1}$ & $1.92 \times 10^{-11}(\mathrm{UM})$ \\
\hline & & & $1.67 \times 10^{-13}(\mathrm{LM})$ \\
\hline Exponent & $n$ & - & 1 \\
\hline \multicolumn{4}{|l|}{ Byerlee yielding } \\
\hline Cohesion & $b$ & $\mathrm{MPa}$ & 60 \\
\hline Friction coefficient & $a$ & - & 0.6 \\
\hline Pre-factor & $\lambda$ & - & 0.1 \\
\hline Maximum yield stress & $\tau_{\max }$ & $\mathrm{MPa}$ & 500 \\
\hline
\end{tabular}

Table 1: Basic reference model parameters. 